\title{
Strong methane point sources contribute a disproportionate fraction of total emissions across multiple basins in the U.S.
}

Daniel H. Cusworth ${ }^{1,2}$, Andrew K. Thorpe ${ }^{3}$, Alana K. Ayasse ${ }^{1,2}$, David Stepp ${ }^{2}$, Joseph Heckler ${ }^{4}$, Gregory P. Asner ${ }^{4,2}$, Charles E. Miller ${ }^{3}$, John W. Chapman ${ }^{3}$, Michael L. Eastwood ${ }^{3}$, Robert O. Green $^{3}$, Benjamin Hmiel ${ }^{5}$, David Lyon ${ }^{5}$, and Riley M. Duren ${ }^{1,2}$

${ }^{1}$ Arizona Institutes for Resilience, University of Arizona, Tucson, AZ, USA

${ }^{2}$ Carbon Mapper, Pasadena, CA, USA

${ }^{3}$ Jet Propulsion Laboratory, California Institute of Technology, Pasadena, CA, USA

${ }^{4}$ Center for Global Discovery and Conservation Science, Arizona State University, Tempe, AZ, USA

${ }^{5}$ Environmental Defense Fund, Austin, TX, USA

Corresponding Author: Daniel H. Cusworth (dcusworth@arizona.edu)

This paper is a non-peer reviewed preprint submitted to EarthArXiv 


\begin{abstract}
Understanding, prioritizing, and mitigating methane $(\mathrm{CH} 4)$ emissions requires quantifying methane budgets from facility scales to regional scales with the ability to differentiate between source sectors. We deployed a tiered observing system for multiple basins in the United States (San Joaquin Valley, Uintah, Denver-Julesberg, Permian, Marcellus). We quantify strong point source emissions (>10 kg CH4 h $\mathrm{h}^{-1}$ ) using airborne high spatial resolution imaging spectrometers, then attribute them to sectors, and assess their intermittency with multiple revisits. We contextualize these point source emissions by comparing to total basin $\mathrm{CH} 4$ fluxes derived from inversion of Sentinel-5p satellite observations. We find that across basins point source make up on average $40 \%$ of the regional flux. We sampled some basins several times across multiple months and years and find a distinct bimodal structure to emission lifetimes: the total point source budget is split nearly in half by short- and long-lived emission events. With the increasing airborne and satellite observing capability planned for the near future, tiered observing systems can more fully account and attribute emission sources, which is needed to effectively and efficiently reduce methane emissions.
\end{abstract}

\title{
1 Introduction
}

Due to its short atmospheric lifetime and strong contribution to global radiative forcing, methane (CH4) has been a focus for near-term climate mitigation efforts (Ocko et al., 2021). Robust, unbiased accounting systems are requisite to prioritizing and validating methane mitigation, ideally from multiple independent data streams. Atmospheric observations of $\mathrm{CH} 4$ are key to these actionable information efforts, as observed $\mathrm{CH} 4$ concentrations are used to quantify emission rates and attribute emissions to sources independent of inventory or emissions factor estimates. Findings from many independent research efforts have shown that $\mathrm{CH} 4$ emissions 
across multiple sectors follow heavy-tailed distributions (Zavala-Ariaza et al., 2017; Frankenberg et al., 2016; Duren et al., 2019; Cusworth et al., 2021), meaning that a small fraction of emission sources emit at disproportionately higher rates than the full population of emitters. Methane sources can be intermittent or persistent in duration, which may be associated with anticipated and short-lived process-driven releases compared to long-lived excess emissions due to abnormal or otherwise avoidable operating conditions such as malfunctions or leaks (Cusworth et al., 2021). Isolating populations of large emitters at varying levels of intermittency while contextualizing their contribution to regional budgets creates a clear direction for mitigation focus. This tiered observing system strategy can be deployed in data rich regions where multiple independent layers of observations are jointly leveraged to quantify and isolate emissions, and then drive action.

Advances in $\mathrm{CH} 4$ remote sensing have enabled quantification of emissions from global to facility scales. Generally, these observing systems operate by measuring solar backscattered radiance in shortwave infrared regions where $\mathrm{CH} 4$ is a known absorber. Global mapping satellite missions have been used to identify hotspots and infer global to regional scale $\mathrm{CH} 4$ emission fluxes (Kort et al., 2014; Qu et al., 2021; Lauvaux et al., 2021). In particular, the TROPOspheric Monitoring Instrument (TROPOMI; Veefkind et al., 2012) onboard the Sentinel-5p satellite has proven capable of quantifying fluxes at basin scales (Zhang et al., 2020; Schneising et al., 2020). Due to the kilometer-scale resolution of measurements from these global mapping missions, further attribution to particular facilities or even emission sectors is often not feasible. Less precise, target-mode satellites (e.g., PRISMA, Guanter et al., 2021; GHGSat, Jervis et al., 2021) have proven capable of quantifying very large emissions at $\sim 30 \mathrm{~m}$ scale, allowing for direct emission attribution to facilities or even sub-facility level infrastructure. However, the current generation of CH4 emissions imaging satellites lack the spatial and temporal coverage to provide quantification completeness across multiple basins. Global mapping, high-spatial resolution multi-spectral 
satellites like Sentinel-2 and Landsat are capable of CH4 detection (Varon et al., 2021; Ehret et al., 2021), but only for large emission sources (e.g., $2+\mathrm{t} \mathrm{h}^{-1}$ ) over very bright surfaces.

Airborne imaging spectrometers are remote sensing platforms capable of high spatial resolution ( $3-5 \mathrm{~m}) \mathrm{CH} 4$ plume quantification for point source emissions as low as $5-10 \mathrm{~kg} \mathrm{~h}^{-1}$ depending on flight altitude, which have been validated with multiple controlled release experiments (Thorpe et al., 2021; Thorpe et al., 2016). These instruments are sensitive to concentrated point-source emissions, and less sensitive to the larger diffuse area emissions. Given the heavy-tailed nature of anthropogenic emissions, positive point-source detections above an imaging spectrometer's detection limit may constitute a sizable fraction of the total regional emissions, but independent measurements are needed to provide that context. Therefore, in this study, we flew a combination of the Global Airborne Observatory (GAO) and Next-Generation Airborne Visible/Infrared Imaging Spectrometer (AVIRIS-NG) over multiple CH4 emitting regions between 2019-2021, including the Southern San Joaquin Valley (SJV), the Permian, the Denver-Julesberg (DJ), the Unita, and the southwestern Pennsylvania portion of the Marcellus. We generally mapped each basin at least three times during each campaign to quantify persistence of emission sources. For several basins, we re-surveyed after several months to years to quantify the influence of very long-lived sources and assess trends. We also performed simultaneous regional $\mathrm{CH} 4$ flux inversions based on TROPOMI CH4 retrievals to quantify and contextualize the total $\mathrm{CH} 4$ flux for each survey. With this tiered approach, we are able to quantify the contribution and lifetime of unique point sources by sector on the regional budget, therefore highlighting specific points of action for mitigation.

\section{Results and Discussion}

Survey design 
We mapped five distinct basins using GAO and/or AVIRIS-NG from 2019 to 2021 (Figure 1). AVIRIS-NG and GAO are similarly built instruments that measure solar backscatter between $380-2500 \mathrm{~nm}$ at $5 \mathrm{~nm}$ spectral resolution. Methane concentrations were retrieved in the 2200$2400 \mathrm{~nm}$ CH4-absorbing region using a column-wise matched filter algorithm (Cusworth et al., 2021). Plumes were identified by visual inspection, whose protocols are described in the Supporting Information (SI) Section S1. Emissions rates and uncertainties were quantified using an Integrated Methane Enhancement (IME) algorithm that has been validated against multiple controlled release experiments and independent in situ measurement (Thorpe et al., 2016; Duren et al., 2019; Thorpe et al., 2021). Figure 1 shows example plumes that were detected across multiple basins and across unique sectors. Emission sectors with point source plume characteristics detectable by AVIRIS-NG/GAO include oil and gas $(\mathrm{O} \& \mathrm{G})$, wet manure management from animal feedlots, waste management from high capacity landfills, and coal mine seepage/venting. Other diffuse emissions, including enteric fermentation, dry manure management, wetlands, etc. are not easily detectable with this type of imaging spectrometer. Table 1 provides summary information for each basin, including dates and area flown, number of detected plumes, and estimated emissions. Figure S1 shows each domain and the specific flight line outlines for each survey.

To generate aggregate statistics for plumes that originate from the same facilities, each quantified plume is clustered in space and time with any other detection within $150 \mathrm{~m}$, a typical lateral distance of a well-site that is also within the geolocation uncertainty of the instrument (6$10 \mathrm{~m})$. This process clusters plumes into sources, which can be attributed to facilities or infrastructure. GAO has a boresighted high resolution $(\sim 60 \mathrm{~cm})$ digital airborne camera that we use to attribute sources to specific sectors. For AVIRIS-NG, we use a combination of 3-5 m RGB channels from the imaging spectrometer and Google Earth base imagery for source attribution. For sources with at least three overflights, we apply persistence-weighting to estimate average 
emissions. This weighting scales the average emission rate by persistence $(f)$, or by the number of detections $(M)$ divided by $N$, the number of overflights $(f=M / N)$. We consider three overflights to be the minimum needed to detect a characteristically intermittent source; previous work found that the average intermittency of O\&G emissions in California was $f=0.23$ (Duren et al., 2019). To have a greater than $50 \%$ probability of detecting emissions at that characteristic source, at least three overpasses are needed: $p=1-(1-0.23)^{3}>0.5$. When aggregating emissions for a survey, we sum persistence-weighted source emissions. If there exist sources with less than three overflights in a survey, we sample the distribution of $f$ values for that sector for that survey and assign it to that under-flown source before aggregating. To account for variability in sampling on aggregate emissions, we generate 1000 Monte-Carlo samples for each under-flown source for each survey.

\section{Point and regional CH4 budgets across multiple basins}

Figure $2 \mathrm{a}$ shows the results from the multi-basin surveys, including persistence-adjusted point source emissions compared against (1) total $\mathrm{CH} 4$ fluxes we derived simultaneously from inversion of TROPOMI XCH4 with a particle dispersion model (Fasoli et al., 2018), and (2) bottom-up gridded emission inventories for O\&G, other anthropogenic, and natural sources (Maasakkers et al., 2016; Scarpelli et al., 2020; Ma et al., 2021). Our CH4 flux inversion approach has been validated using independent flux estimates from multiple basins (SI Section S2), and the gridded results for each inversion are shown in Figures S2-S4. All emission estimates are normalized to the area covered by each survey (Table 1). We find that across all basin and time periods, point sources make up on average $40 \%$ of the each basin's total flux. This occurs both O\&G dominant basins like the Permian, but also in basins with more differentiated sources (e.g., Marcellus, DJ, SJV). In particular, in the surveyed area of the Marcellus basin, we ascribe 58\% of 
the regional flux to point sources, which is driven primarily by persistent coal mine venting that makes up $65 \%$ of the point source budget. Venting is an expected and permitted operation, but is a major contributor to regional and national greenhouse gas emissions. The coal venting operations we quantified just in the southwestern portion of Pennsylvania together represent $0.36 \pm 0.13 \mathrm{Tg}$ $\mathrm{a}^{-1}$. This constitutes is $1.3 \%$ of EPA's national CH4 bottom-up inventory for 2019 (26.9 Tg) and $3.4 \%$ of the national energy sector emission estimates $(10.7 \mathrm{Tg})$, which includes all fossil-fuel CH4 sources (EPA, 2021).

Figure 2 a shows that the bottom-up inventory generally underestimates the total $\mathrm{CH} 4$ flux derived from TROPOMI; a result consistent with previous top-down analyses (Alvarez et al., 2018). This discrepancy is due to several factors, including the age of the inventory (2012-2016) which may underestimate current activity information and emission factors, especially in basins with increasing production (e.g., the Permian). Geospatial information included in the inventory may also be inaccurate or outdated, which biases comparisons to surveys that only look at subregions of full basins. However, Figure $2 \mathrm{c}$ shows the relative contribution of O\&G, waste, manure management, and coal emissions in each region, as quantified by our airborne surveys and the bottom-up inventory. Here, relative contributions are more consistent with the bottom-up inventory across campaigns. A few caveats apply, especially in regard to manure management. For example, during the July 2021 DJ survey, the contributions from point source manure emissions $\left(44 \% ; 2,200 \pm 970 \mathrm{~kg} \mathrm{~h}^{-1}\right)$ were nearly equal to $\mathrm{O} \& \mathrm{G}$ emissions $(50 \% ; 2,490 \pm 1100 \mathrm{~kg}$ $\left.\mathrm{h}^{-1}\right)$. When the basin was re-surveyed in Sep-Oct 2021, the contribution from manure was only 875 $\pm 280 \mathrm{~kg} \mathrm{~h}^{-1}$ or $16 \%$ of the total $\left(5,370 \pm 1,700 \mathrm{~kg} \mathrm{~h}^{-1}\right)$, due to both a reduction in manure emissions and an increase in O\&G emissions $\left(79 \% ; 4,250 \pm 1400 \mathrm{~kg} \mathrm{~h}^{-1}\right)$. The bottom-up inventory estimates only $6.5 \%$ of emissions from manure in this same region, an underestimate compared to either airborne DJ survey. According to measurements from the Greely Airport (MesoWest, 2022), the 
average local noontime temperature dropped $5^{\circ} \mathrm{C}$ between Summer and Fall campaigns. More study is needed to verify if seasonal variability can explain the apparent discrepancy with the bottom-up inventory or if manure management is a much larger relative emitter than expected.

Table 2 lists observed O\&G point sources by upstream and midstream supply-chain segment: production site (well-site or tank battery at well-site); pipeline (mostly gathering with some transmission), compression (gathering and transmission), processing plants, and other or unidentifiable $O \& G$ infrastructure. For every survey, production makes up the majority of the O\&G emission budget, although its contribution is highly variable, ranging from 39 to $82 \%$. Compression and processing make up a smaller percentage of the budget $(7.1-35 \%$ and $0-11 \%$, respectively), which is consistent with top-down studies (Alvarez et al., 2018). One discrepancy is in the Permian Basin, where compression and processing represent $19-35 \%$ and $6-11 \%$ of the $\mathrm{O} \& \mathrm{G}$ budget, respectively. The higher concentration of emissions in the midstream sector in the Permian is a result observed previously and is likely the result of insufficient haul-away capacity to match the fast increase in production in the basin (Lyon et al., 2021; Cusworth et al., 2021).

Gathering pipeline emissions are largely variable in their O\&G contribution $(2.9-45 \%$; Table 2) across basins and even within basins across time. On average, gathering pipelines make up $23 \%$ of O\&G point-sources across campaigns and are the second largest source of $\mathrm{CH} 4$ after production. In the U.S., enforcement authority for gathering pipelines fall under the Department of Transportation Pipeline and Hazardous Materials Safety Administration (PHMSA). Fractured enforcement jurisdictions across separate $O \& G$ supply-chain segments are a major challenge to leak mitigation. A specific example of multiple jurisdictional authority intervention occurred with a persistent pipeline leak (100-200 $\left.\mathrm{kg} \mathrm{h}^{-1}\right)$ we detected with GAO in the DJ basin on 4 separate dates during the Summer of $2021\left(40.022^{\circ} \mathrm{N},-104.553^{\circ} \mathrm{W}\right.$; Figure S5). After multiple detections, we notified the Colorado Department of Public Health (CDPHE), the Colorado Oil and Gas 
Conservation Commission (COGCC), Colorado State University (CSU), and PHMSA. CSU and COGCC verified the detection with a handheld gas analyzer, excavated the area, discovering a half inch hole in the gathering pipeline, then notified the operator who shut in, blew down, and repaired the pipeline. COGCC only has jurisdiction for cleanup of hazardous waste associated with a leak, and PHMSA as a safety regulator focuses on injury, damage, and property loss due to these types of events. COGCC issued a spill/release report (COGCC, 2021), but since this pipeline leak occurred in an isolated area, no PHMSA report was required. In any event, since multiple enforcement agencies or authorities may have varying levels of jurisdiction for emission events, having precisely geolocated information is critical for handing the data off to the appropriate users, especially for the gathering pipeline sector.

\section{Impact of long-lived emission sources}

In Figure 2, we use persistence to calculate time-averaged emission rates at each source location. A related metric is the lifetime of each emission source for sources where multiple plumes were detected across independent flight days. We define lifetime as the length of time between the

first and the last plume detection for a given source. In order to compare across multiple campaigns, we normalize lifetime by the duration of its respective campaign or campaigns. For example, if the lifetime of source is 6 days for a 10-day campaign, then the normalized lifetime is 0.6. Due to revisit feasibility during field campaigns, not every source can be flown on the first and last days of each campaign, so this normalization may incur a lifetime shortening bias. However, this potential source of bias becomes negligible when looking at long duration field campaigns across multiple months and years.

Figure 3 shows the distribution of source lifetimes for individual campaigns. The distribution of lifetimes for individual campaigns (Figure 3a) is nearly flat, but shows a slight 
decrease as lifetimes get longer, except for a small jump around 0.8 , due to persistent coal venting emissions in the Marcellus (Table 1). This overall flat structure is likely due to sampling conditions during individual campaigns; uniform revisit frequency for sources within campaigns is often technically infeasible given weather and other logistical considerations. Therefore, we also calculate emission lifetimes for multi-month (DJ Summer/Fall 2021; Permian Summer/Fall 2021; SJV Summer/Fall 2020) and multi-year campaigns (Permian 2019-2021; SJV 2020-2021) by reclustering plumes to emission sources across the longer multi-month or year temporal domain (Figure 3b-c). For multi-month campaigns, a clear bimodal structure appears centered around a short-lifetime mode (0-0.2) and a long-lifetime mode (0.7-1.0). The bimodal structure persists for multi-year campaigns (Permian 2019-2021; SJV 2020-2021), showing that some sources show sustained emission activity over long timescales.

Short and long-lived sources both contribute significant fractions to total emissions. Figure $3 \mathrm{~d}$ shows the cumulative contribution of emissions from each normalized lifetime bin to the total. For multi-month and year campaigns, sources with normalized lifetimes greater than 0.7 contribute $39-54 \%$ to the total. Shorter-lived sources (0-0.3 normalized lifetime) contribute $44-49 \%$ to the total. For effective mitigation, this means that within the point source population of emissions, topdown monitoring solutions need temporal sampling capability to capture both lifetime modes. Long-lived sources may be indicative of leaks, malfunctions, or some known releases (e.g., permitted coal venting). Short-lived sources may be indicative of expected releases (e.g., temporary maintenance) or malfunctions triggered by variable process conditions (e.g., pressure buildup). A revisit strategy with long revisit intervals (e.g., months) would not be able to easily distinguish between these lifetime modes and could potentially miss a sizable contribution from emissions that are short-lived. 


\section{Emission trends}

The multi-year campaigns in the Permian and SJV allow us to look at basin-scale trends. In the Permian, the spatial overflight domains across campaigns are not consistent. The Fall 2019 campaign mapped a much wider area of the Permian and subsequent campaigns in 2020-2021 focused on areas of large activity that were originally identified in 2019. We therefore look at just the overlapping regions flown among all campaigns. Within the region of overlap (Figure S6), the point-source aggregated emissions from 2019 are much higher $\left(0.84 \pm 0.27 \mathrm{Tg} \mathrm{a}^{-1}\right)$ than in subsequent revisits in Summer 2020, Summer 2021, and Fall $2021\left(0.52 \pm 0.15 \mathrm{Tg} \mathrm{a}^{-1} ; 0.41 \pm 0.12\right.$ $\mathrm{Tg} \mathrm{a}^{-1} ; 0.48 \pm 0.19 \mathrm{Tg} \mathrm{a}^{-1}$; respectively). Reduction from high Fall $2019 \mathrm{CH} 4$ emissions, quantified by both airborne and satellite data, may be due to multiple causes. COVID-19 and oil market impacts were previously observed to correlate with reduced flaring activity and fewer well completions, which can impact CH4 emissions (Lyon et al., 2021). In addition, since 2019, aerial and ground-based data generated from this and other studies have been shared with operators on an ongoing basis (e.g., via PermianMap.org). Other operators have funded independent aerial measurements and have claimed emission reductions based on those results (e.g., ExxonMobil, 2020). Another cause could be the heterogeneity of operators, leases, and supply-chain activity in the Permian contributing to general high variability in emissions. For example, Fall 2019 aggregated Permian airborne point-source emissions were as much as a factor of 2 variable on daily to weekly time scales (Cusworth et al., 2021). More long-term trend and attribution analysis is needed to disentangle trends from general variability for the Permian.

A strong relative reduction (69-76\%) in point-source emissions occurred in SJV between Summer 2020 and Fall 2021, along with a 20\% reduction in the total flux (Table 1). This also corresponds to a $81 \%$ emission reduction for point sources in SJV observed with AVIRIS-NG during the California Methane Survey (12,600 $\pm 3,700 \mathrm{~kg} \mathrm{~h}^{-1}$; Duren et al., 2019). The decrease 
in emissions is driven by reductions in both the O\&G and livestock sector. Since 2016, many digesters (impermeable liners) were placed over manure lagoons across multiple dairies in southern Kern County (CDFA, 2021). This appears to have had a sizable impact, as emissions from this sector reduced in Summer 2021 from 3,500 $\pm 1,100 \mathrm{~kg} \mathrm{~h}^{-1}$ to $166 \pm 77 \mathrm{~kg} \mathrm{~h}^{-1}$ in 2021 . There was not complete overlap in these regions across campaigns, and dairies were not sampled during the Fall 2020 campaign. However, almost all manure CH4 sources detected in Summer 2020 were re-flown in Fall 2021, indicating that the trend is not biased from sampling, though there could be a contribution from seasonality of emissions, which may also be driving manure emission variability in the DJ basin. O\&G emissions dropped from 6,920-5,560 $\mathrm{kg} \mathrm{h}^{-1}$ between Summer-Fall 2020 campaigns to $2,170 \pm 1,000 \mathrm{~kg} \mathrm{~h}^{-1}$ in 2021. During the Fall 2020 campaign, researchers from the California Air Resources Board, Carbon Mapper, and JPL shared CH4 plume detections with individual operators and solicited feedback regarding causes of emissions and any mitigation efforts. Reductions in emissions between 2020 and 2021 could be driven by this outreach effort, though sustained monitoring is needed to confirm that sources remain low or nonemitting into the future.

\section{Conclusions}

No single instrument, measurement platform, or network is capable of full characterization of $\mathrm{CH} 4$ emissions within a basin or region. Therefore, tiered-observing systems are needed to adequately constrain emission budgets and prioritize areas and infrastructure for mitigation. We demonstrated an application of this system using remote sensing platforms across multiple basins in the U.S during 2019-2021 High-resolution and emitting CH4 point sources were quantified with the GAO and AVIRIS-NG imaging spectrometers. These point sources were attributed to facilities and/or infrastructure using a high-resolution visible context camera or other visible imagery from 
AVIRIS/GAO and Google Earth. Near simultaneous basin-wide CH4 fluxes were estimated from atmospheric inversions using TROPOMI and a particle dispersion model. These regions were flown multiple times over weeks, month, and in some cases, years. The results from this multibasin tiered analysis shows that point sources make up around $40 \%$ of the total CH4 flux (13-67\% range), and highlights the heavy-tailed nature of point sources across many regions and sectors. It is likely that if a basin is known to be made of up of any combination of emission sectors that are characteristically heavy-tailed (e.g., O\&G, coal, manure management, waste), there is a strong likelihood that point sources will make up a significant fraction of the entire region's emissions.

We show that point-sources tend to pertain to equally contributing short and long lived lifetime modes, which has implications for designing monitoring strategies. Therefore, the global scalability of tiered observing systems depends on the completeness of atmospheric observations, which entails sensitivity to emissions, temporal revisit, and spatial completeness. In addition to aircraft campaigns, point-source quantification will rapidly expand with emerging satellite missions (e.g., Carbon Mapper; 2023 launch). Total basin flux estimation will also improve with wide-swath mapping missions (e.g., MethaneSat; 2023 launch). Where available, ground-based networks are also critical for quantifying regional emissions (Yadav et al., 2019), and for validation of remote-sensing platforms. As these data products are refined and made freely available to the public in easily interpretable formats, there exists great potential in handing off atmospherically informed datasets to appropriate operators and agencies to ultimately reduce methane emissions.

Data Availability. Methane plumes and emissions are available to visualize and download at carbonmapperdata.org as well as multiple data repositories (https://doi.org/10.1021/acs.estlett.1c00173; $\quad$ https://doi.org/10.5281/zenodo.5606120). TROPOMI CH4 retrievals were accessed via the Copernicus Open Access Hub 
(https://scihub.copernicus.eu/ ). Fossil fuel prior emission inventories are available for download at https://doi.org/10.7910/DVN/HH4EUM. Wetland emission prior inventories are available at (https://doi.org/10.3334/ORNLDAAC/1502). The EPA gridded methane inventory is available for download at https://www.epa.gov/ghgemissions/gridded-2012-methane-emissions. The STILT atmospheric transport model is available for download at https://github.com/uataq/stilt.

Acknowledgments. Funding for flight operations and/or data analysis referenced in this paper was supported by NASA's Carbon Monitoring System and Advanced Information System Technology programs as well as RMI, Environmental Defense Fund, California Air Resources Board (CARB), the University of Arizona, and the US Climate Alliance. Funding for Colorado overflights was provided by the Mark Martinez and Joey Irwin Memorial Public Projects Fund with the support of the Colorado Oil and Gas Conservation Commission and the Colorado Department of Public Health and Environment (CDPHE). The Carbon Mapper team also acknowledges the support of their sponsors including the High Tide Foundation, Bloomberg Philanthropies, Grantham Foundation and other philanthropic donors. The authors thank colleagues at CARB, CDPHE, Colorado State University, University of Utah, EDF and Pennsylvania Department of Environmental Protection for input on survey design and analysis for the California, Colorado, Utah, Permian, and Pennsylvania studies, respectively. Portions of this work research was carried out at the Jet Propulsion Laboratory, California Institute of Technology, under a contract with the National Aeronautics and Space Administration (80NM0018D0004). We thank Dan Zimmerle for on the ground insights to pipeline leak discussed in the text. We thank Daniel Varon for conversations regarding inversion frameworks and validation. The Global Airborne Observatory (GAO) is managed by the Center for Global Discovery and Conservation Science at Arizona State 
University. The GAO is made possible by support from private foundations, visionary individuals, and Arizona State University.

Competing interests. The authors declare no conflicts of interest.

\section{References}

Alvarez, R.A., Zavala-Araiza, D., Lyon, D.R., Allen, D.T., Barkley, Z.R., Brandt, A.R., Davis, K.J., Herndon, S.C., Jacob, D.J., Karion, A. and Kort, E.A., 2018. Assessment of methane emissions from the US oil and gas supply chain. Science, 361(6398), pp.186-188.

CDFA, 2021. California Department of Food and Agriculture, DDRDP Report 2021, https://www.cdfa.ca.gov/oefi/ddrdp/docs/DDRDP_Report_March2021.pdf, Last Accessed Jan 28,2021

COGCC, COGIS - SPILL OR RELEASE Information, URL https://cogcc.state.co.us/weblink/results.aspx?id=480338, Last Accessed Feb 3, 2022

Cusworth, D.H., Duren, R.M., Thorpe, A.K., Olson-Duvall, W., Heckler, J., Chapman, J.W., Eastwood, M.L., Helmlinger, M.C., Green, R.O., Asner, G.P. and Dennison, P.E., 2021. Intermittency of large methane emitters in the Permian Basin. Environmental Science \& Technology Letters, 8(7), pp.567-573.

Duren, R.M., Thorpe, A.K., Foster, K.T., Rafiq, T., Hopkins, F.M., Yadav, V., Bue, B.D., Thompson, D.R., Conley, S., Colombi, N.K. and Frankenberg, C., 2019. California's methane super-emitters. Nature, 575(7781), pp.180-184.

Ehret, T., De Truchis, A., Mazzolini, M., Morel, J.M., d'Aspremont, A., Lauvaux, T. and Facciolo, G., 2021. Global Tracking and Quantification of Oil and Gas Methane Leaks from Recurrent Sentinel-2 Imagery. arXiv preprint arXiv:2110.11832.

EPA, Greenhouse Gas Inventory Data Explorer:

https://cfpub.epa.gov/ghgdata/inventoryexplorer/\#iallsectors/allsectors/methane/inventsect/curre nt, Last accessed Dec 15, 2021

ExxonMobil, "ExxonMobil field testing new comprehensive methane monitoring technologies," April 9, 2020, https://corporate.exxonmobil.com/News/Newsroom/Newsreleases/2020/0409_ExxonMobil-field-testing-new-comprehensive-methane-monitoringtechnologies, Last Accessed Feb 1, 2022 
Fasoli, B., Lin, J.C., Bowling, D.R., Mitchell, L. and Mendoza, D., 2018. Simulating atmospheric tracer concentrations for spatially distributed receptors: updates to the Stochastic Time-Inverted Lagrangian Transport model's R interface (STILT-R version 2). Geoscientific Model Development, 11(7), pp.2813-2824.

Frankenberg, C., Thorpe, A.K., Thompson, D.R., Hulley, G., Kort, E.A., Vance, N., Borchardt, J., Krings, T., Gerilowski, K., Sweeney, C. and Conley, S., 2016. Airborne methane remote measurements reveal heavy-tail flux distribution in Four Corners region. Proceedings of the national academy of sciences, 113(35), pp.9734-9739.

Guanter, L., Irakulis-Loitxate, I., Gorroño, J., Sánchez-García, E., Cusworth, D.H., Varon, D.J., Cogliati, S. and Colombo, R., 2021. Mapping methane point emissions with the PRISMA spaceborne imaging spectrometer. Remote Sensing of Environment, 265, p.112671.

Jervis, D., McKeever, J., Durak, B.O., Sloan, J.J., Gains, D., Varon, D.J., Ramier, A., Strupler, M. and Tarrant, E., 2021. The GHGSat-D imaging spectrometer. Atmospheric Measurement Techniques, 14(3), pp.2127-2140.

Kort, E.A., Frankenberg, C., Costigan, K.R., Lindenmaier, R., Dubey, M.K. and Wunch, D., 2014. Four corners: The largest US methane anomaly viewed from space. Geophysical Research Letters, 41(19), pp.6898-6903.

Lauvaux, T., Giron, C., Mazzolini, M., d'Aspremont, A., Duren, R., Cusworth, D., Shindell, D. and Ciais, P., 2021. Global Assessment of Oil and Gas Methane Ultra-Emitters. arXiv preprint arXiv:2105.06387.

Lyon, D.R., Hmiel, B., Gautam, R., Omara, M., Roberts, K.A., Barkley, Z.R., Davis, K.J., Miles, N.L., Monteiro, V.C., Richardson, S.J. and Conley, S., 2021. Concurrent variation in oil and gas methane emissions and oil price during the COVID-19 pandemic. Atmospheric Chemistry and Physics, 21(9), pp.6605-6626.

Ma, S. et al. Satellite constraints on the latitudinal distribution and temperature sensitivity of wetland methane emissions. AGU Advances, 2, e2021AV000408. https://doi.org/10.1029/2021AV000408 (2021)

Maasakkers, J.D. et al. Gridded national inventory of US methane emissions. Environmental science \& technology, 50(23), pp.13123-13133. (2016)

MesoWest, KGXY Station Weather Data, https://mesowest.utah.edu/cgibin/droman/download_api2.cgi?stn=KGXY\&year1=2022\&day $1=31 \&$ month1=1\&hour1=14\&ti metype $=$ LOCAL\&unit $=0$, Last Accessed Jan 31, 2022

Ocko, I.B., Sun, T., Shindell, D., Oppenheimer, M., Hristov, A.N., Pacala, S.W., Mauzerall, D.L., Xu, Y. and Hamburg, S.P., 2021. Acting rapidly to deploy readily available methane mitigation measures by sector can immediately slow global warming. Environmental Research Letters, 16(5), p.054042. 
Qu, Z., Jacob, D.J., Shen, L., Lu, X., Zhang, Y., Scarpelli, T.R., Nesser, H., Sulprizio, M.P., Maasakkers, J.D., Bloom, A.A. and Worden, J.R., 2021. Global distribution of methane emissions: a comparative inverse analysis of observations from the TROPOMI and GOSAT satellite instruments. Atmospheric Chemistry and Physics, 21(18), pp.14159-14175.

Scarpelli, T.R. et al. A global gridded $(0.1 \times 0.1)$ inventory of methane emissions from oil, gas, and coal exploitation based on national reports to the United Nations Framework Convention on Climate Change. Earth System Science Data, 12(1), 563-575. (2020)

Schneising, O., Buchwitz, M., Reuter, M., Vanselow, S., Bovensmann, H. and Burrows, J.P., 2020. Remote sensing of methane leakage from natural gas and petroleum systems revisited. Atmospheric Chemistry and Physics, 20(15), pp.9169-9182.

Thorpe, A.K., Frankenberg, C., Aubrey, A.D., Roberts, D.A., Nottrott, A.A., Rahn, T.A., Sauer, J.A., Dubey, M.K., Costigan, K.R., Arata, C. and Steffke, A.M., 2016. Mapping methane concentrations from a controlled release experiment using the next generation airborne visible/infrared imaging spectrometer (AVIRIS-NG). Remote Sensing of Environment, 179, pp.104-115.

Thorpe, A.K., O'Handley, C., Emmitt, G.D., DeCola, P.L., Hopkins, F.M., Yadav, V., Guha, A., Newman, S., Herner, J.D., Falk, M. and Duren, R.M., 2021. Improved methane emission estimates using AVIRIS-NG and an Airborne Doppler Wind Lidar. Remote Sensing of Environment, 266, p.112681.

Varon, D.J., Jervis, D., McKeever, J., Spence, I., Gains, D. and Jacob, D.J., 2020. Highfrequency monitoring of anomalous methane point sources with multispectral Sentinel-2 satellite observations. Atmos. Meas. Tech. Discuss, 2020, pp.1-21.

Veefkind, J.P. et al. TROPOMI on the ESA Sentinel-5 Precursor: A GMES mission for global observations of the atmospheric composition for climate, air quality and ozone layer applications. Remote sensing of environment, 120, 70-83. (2012)

Yadav, V. et al. Spatio-temporally resolved methane fluxes from the Los Angeles Megacity. Journal of Geophysical Research: Atmospheres, 124(9), 5131-5148. (2019)

Zavala-Araiza, D., Alvarez, R.A., Lyon, D.R., Allen, D.T., Marchese, A.J., Zimmerle, D.J. and Hamburg, S.P., 2017. Super-emitters in natural gas infrastructure are caused by abnormal process conditions. Nature communications, 8(1), pp.1-10.

Zhang, Y., Gautam, R., Pandey, S., Omara, M., Maasakkers, J.D., Sadavarte, P., Lyon, D., Nesser, H., Sulprizio, M.P., Varon, D.J. and Zhang, R., 2020. Quantifying methane emissions from the largest oil-producing basin in the United States from space. Science Advances, 6(17), p.eaaz5120. 
Table 1. Summary of basins surveyed and methane $(\mathrm{CH} 4)$ results

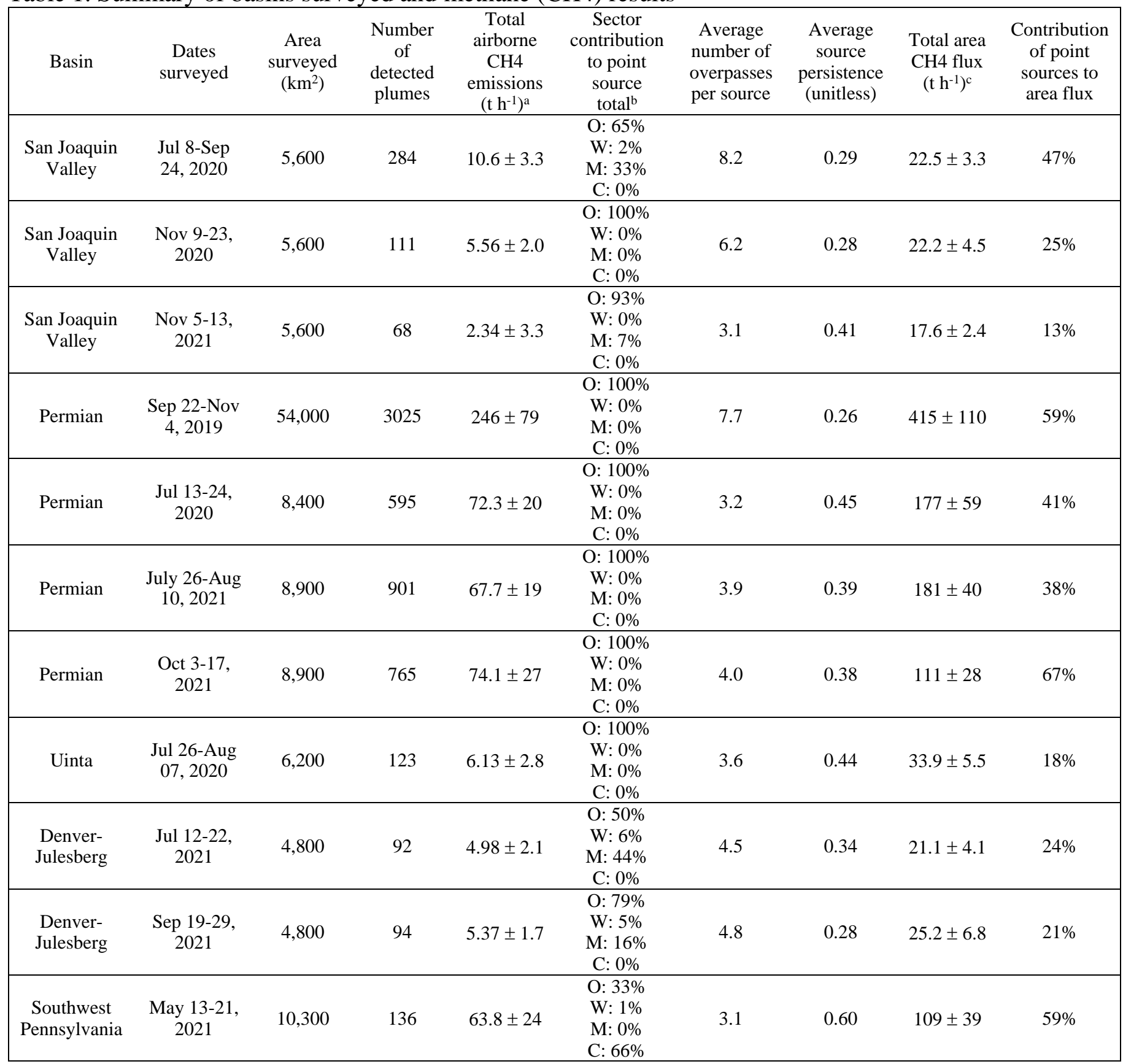

aTotal airborne emissions calculated by aggregated persistence-averaged source emissions within each observing domain.

bO: Oil\&Gas, W: Waste Management, M: Wet Manure Management, C: Coal

'Total area flux estimated through inversion of TROPOMI XCH4 (methods described in Section S2). 
Table 2. Oil and Gas emission contributions from various supply-chain components

\begin{tabular}{|c|c|c|c|c|c|c|c|}
\hline Basin & Dates surveyed & $\begin{array}{c}\text { O\&G point- } \\
\text { source total } \\
\left(\mathrm{t} \mathrm{h}^{-1}\right)\end{array}$ & $\begin{array}{l}\text { Production } \\
(\%)\end{array}$ & $\begin{array}{c}\text { Compression } \\
(\%)\end{array}$ & $\begin{array}{l}\text { Gathering } \\
\text { pipelines } \\
(\%)\end{array}$ & $\begin{array}{l}\text { Processing } \\
(\%)\end{array}$ & $\begin{array}{l}\text { Other } \\
(\%)\end{array}$ \\
\hline San Joaquin Valley & $\begin{array}{c}\text { Jul 8-Sep 24, } \\
2020\end{array}$ & $6.92 \pm 2.1$ & 43 & 7 & 45 & 0 & 5 \\
\hline San Joaquin Valley & Nov 9-23, 2020 & $5.56 \pm 2.0$ & 39 & 16 & 41 & 2 & 2 \\
\hline San Joaquin Valley & Nov 5-13, 2021 & $2.17 \pm 1.0$ & 66 & 11 & 23 & 0 & 0 \\
\hline Permian & $\begin{array}{c}\text { Sep 22-Nov 4, } \\
2019 \\
\end{array}$ & $246 \pm 79$ & 50 & 19 & 23 & 9 & 0 \\
\hline Permian & Jul 13-24, 2020 & $72.3 \pm 20$ & 39 & 35 & 20 & 6 & 0 \\
\hline Permian & $\begin{array}{c}\text { July } 26-\text { Aug } 10, \\
2021\end{array}$ & $67.7 \pm 19$ & 43 & 31 & 19 & 7 & 0 \\
\hline Permian & Oct 3-17, 2021 & $74.1 \pm 27$ & 39 & 32 & 8 & 11 & 11 \\
\hline Uinta & $\begin{array}{c}\text { Jul 26-Aug 07, } \\
2020 \\
\end{array}$ & $6.13 \pm 2.8$ & 59 & 2 & 34 & 5 & 0 \\
\hline Denver-Julesberg & Jul 12-22, 2021 & $2.54 \pm 1.1$ & 71 & 12 & 7 & 9 & \\
\hline Denver-Julesberg & $\begin{array}{c}\text { Sep 19-29, } \\
2021\end{array}$ & $4.25 \pm 1.4$ & 51 & 13 & 28 & 9 & 0 \\
\hline $\begin{array}{c}\text { Southwest } \\
\text { Pennsylvania }\end{array}$ & $\begin{array}{c}\text { May 13-21, } \\
2021 \\
\end{array}$ & $20.9 \pm 7.8$ & 82 & 15 & 3 & 0 & 0 \\
\hline $\begin{array}{l}\text { Average across } \\
\text { campaigns }\end{array}$ & & & 53 & 18 & 23 & 5 & 2 \\
\hline
\end{tabular}


Basins surveyed between 2019-2021

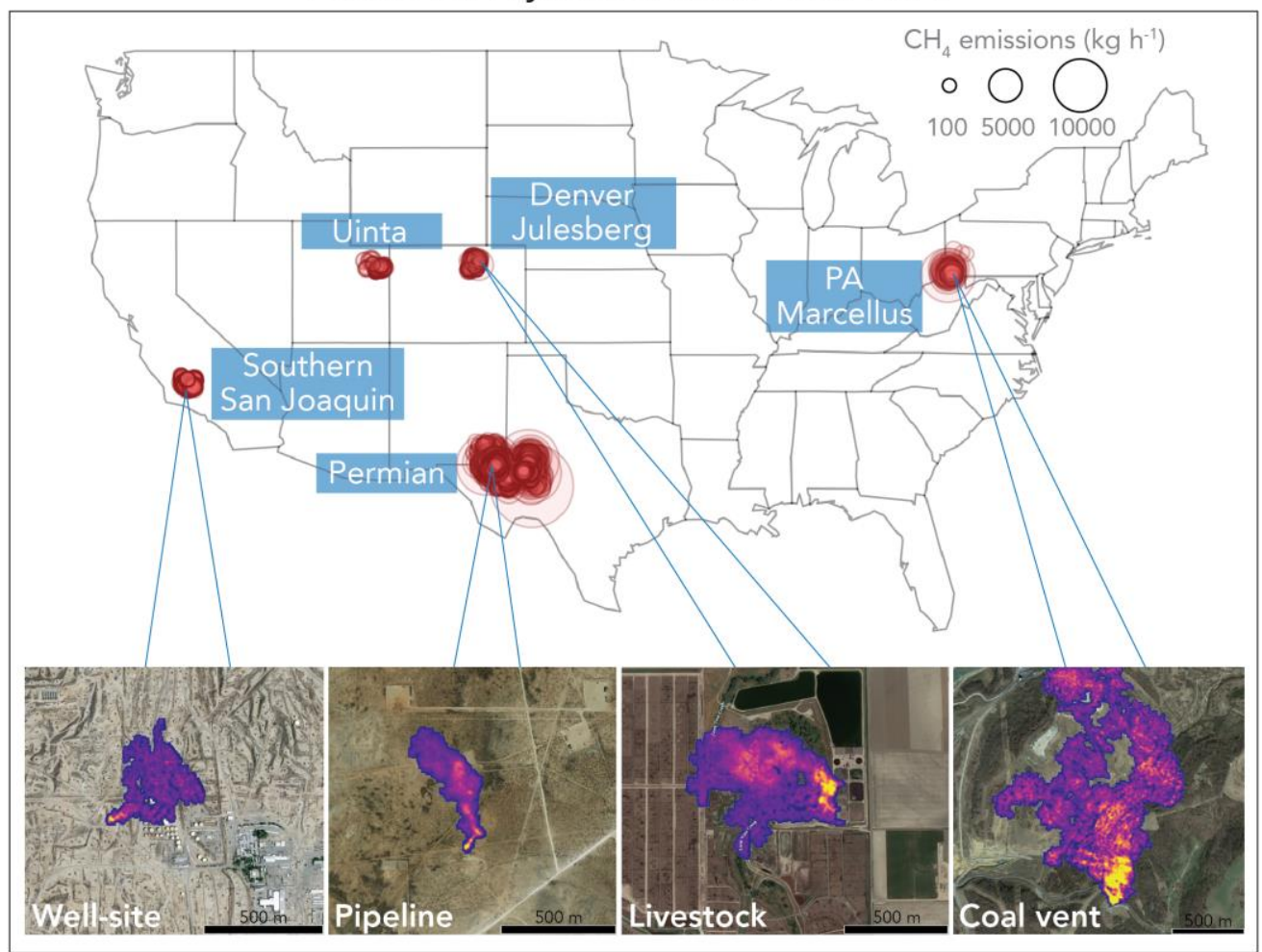

Figure 1. Major basins surveyed between 2019-2021 with either the GAO or AVIRIS-NG airborne imaging spectrometers. Bottom panels show representative $\mathrm{CH} 4$ point source plumes from various emission sources, including a well-site, pipeline, manure management/livestock, and a coal vent. 
Summary of methane emissions for each surveyed basin
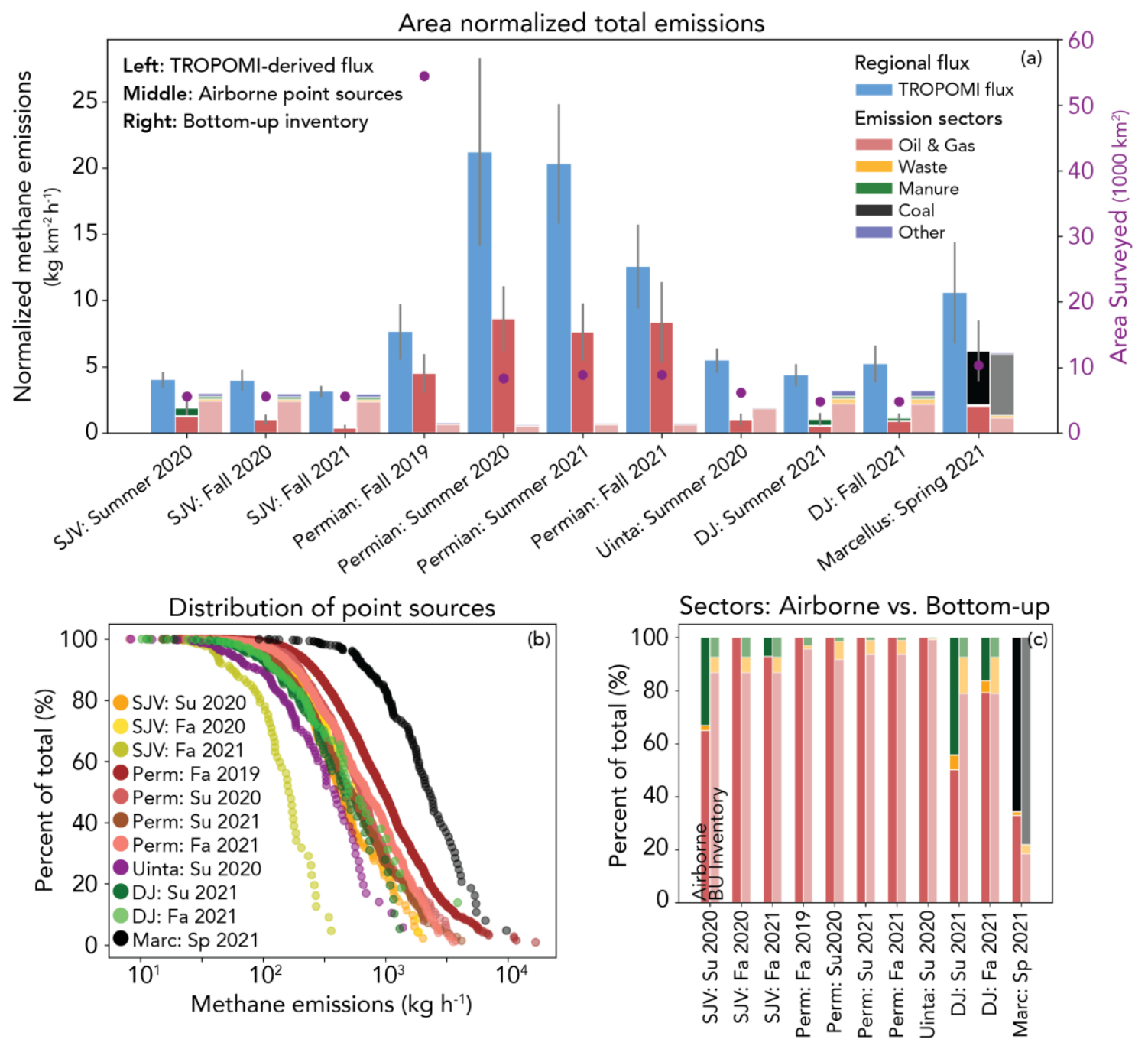

Figure 2. Summary statistics for each basin surveyed between 2019-2021 (Figure 1). Panel (a) shows a comparison between aggregated point source emissions for each campaign with a topdown spatially/temporally synchronous TROPOMI flux inversion and bottom-up emission from the 2012 EPA gridded inventory. Panel (b) shows the cumulative distribution of airborne plume emissions quantified for each campaign. Panel (c) shows the relative sector breakdown between airborne plume emissions and the bottom-up inventory for the following emission sectors: oil \& gas, waste management, manure management, and coal. 

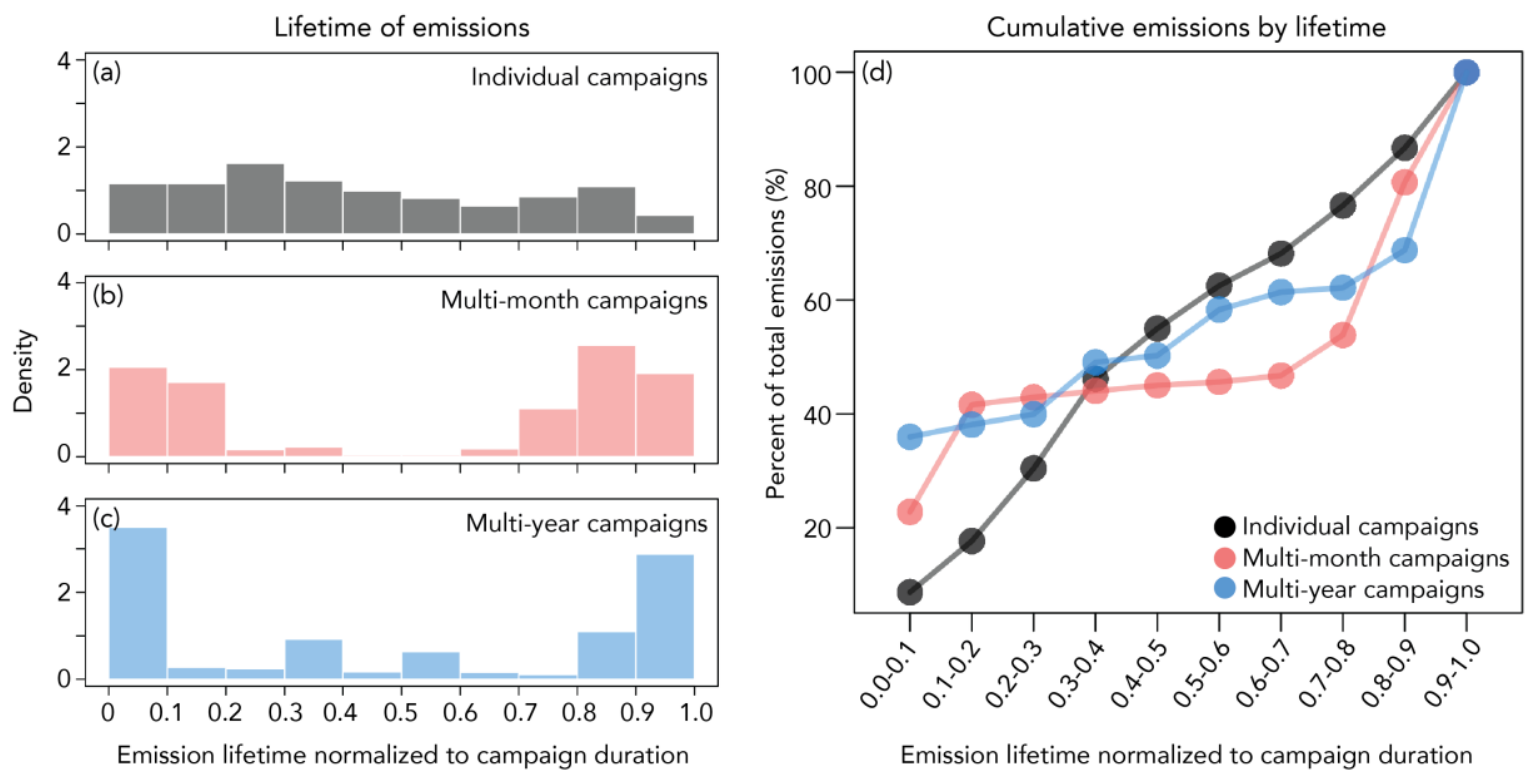

Figure 3. Lifetime of emission sources. Panel (a) shows the normalized lifetime (quantified duration of an emissions divided by length of campaign) of emissions across all campaigns. Panel (b) shows the normalized lifetime for multi-month campaigns (i.e., 2020 Summer/Fall San Joaquin Valley; 2021 Summer/Fall Permian Basin; 2021 Summer/Fall Denver-Julesberg Basin). Panel (c) shows the normalized lifetime for multi-year campaigns (i.e., 2020-2021 San Joaquin Valley; 2019-2021 Permian Basin). Panel (d) shows the cumulative emissions binned by normalized lifetime for panels (a)-(c). 
Supporting Information 
Section S1. Plume identification and source attribution protocols

The plume discrimination and attribution approach closely resembles the methodology used

3 in Cusworth et al. (2021). For plume identification, we generate full scene CH4 maps (Figure S8).

4 These maps are used in conjunction with RGB imagery from the imaging spectrometer to identify

5 the origin of plumes. A positive plume detection is recorded if a cluster of $\mathrm{CH} 4$ enhancements

6 corresponds to a plume-like structure and if these enhancements are not exactly correlated to

7 obvious surface confusers (e.g., rooftops, roads, water bodies, clouds, etc.). The origin of a

8 positively identified plume corresponds to a region of high relative plume enhancement that

9 corresponds to a plausible source location (e.g., tank battery, vent stack) as identified with

10 comparison to available RGB layers.

11 For source attribution, we used a combination of these RGB layers (DIMAC $(\sim 60 \mathrm{~cm})$ imagery,

12 AVIRIS-NG/GAO RGB, Google Earth). Three human analysts followed the classification

13 protocols:

14 - Sites were classified as "Production" if they were clearly associated with well pad 15 infrastructure (well heads, pumpjacks, well completions, tanks at production sites). Sources

16 that were visibly connected to tanks at production sites were labelled "tanks" while all other

17 sites were labelled "well-site."

18 - Sites were classified as "Gathering and Boosting" if they were clearly associated with

19 gathering pipelines or any infrastructure within a compressor station's footprint. For example,

20 if a tank at a compressor station was detected as a source, it was labelled "compression."

21 - Sites were classified as "Processing plants" if any sources were detected within the footprint $22 \quad$ of the processing plant.

23 - Sites were classified as "Gas power plants" if any sources were detected within the footprint 24 of a gas power plant 
$25-$ - Sites were classified as "livestock" if any sources were detected at confined animal feeding 26 operations (CAFOs), including manure lagoons and pits.

27 - Sites were classified as "landfills" if plume were detected within the active, intermediate, or 28 final cover faces, or gas capture system within the footprint of a landfill.

$29-\quad$ Sites were classified as "coal" if plumes were clearly emanating from coal mine vents or if $30 \quad$ large diffuse enhancements were detected from non-vent related coal infrastructure

32 Examples of classified sources are shown in Figure S9-S10. We show RGB imagery for each 33 platform (DIMAC, AVIRIS-NG/GAO, Google Earth), and how the source was classified. Sources 34 where a clear determination could not be made remained unlabeled. All plume imagery is available 35 for visualization and download at carbonmapperdata.org

36

37 
Section S2. TROPOMI Flux Inversion

\section{Section S2.1 Inversion algorithm}

We infer gridded $\mathrm{CH} 4$ emission fluxes using TROPOMI XCH4 over roughly the same time

42 period as an airborne campaign. To ensure sufficient samples to constrain regional fluxes, we

43 performed TROPOMI inversions for two months surrounding each campaign. We use the

44 Stochastic Time-Inverted Lagrangian Transport model (STILT; Fasoli et al., 2018), driven by

45 meteorological reanalysis wind fields. We use the High Resolution Rapid Refresh (HRRR) $3 \times 3$

$46 \mathrm{~km}$ product, which is available at a 3 hourly time resolution

47 (https://www.ready.noaa.gov/READYmetdata.php). The STILT model simulates an influence

48 function or "footprint" at a receptor by releasing an ensemble of particles backwards in time along

49 the winds. Receptors represent instantaneous atmospheric observations. Footprints can be thought

50 of as the sensitivity that an observation had to any upwind emissions in both space and time.

51 Therefore, a single atmospheric observation (y) can be represented by the following relation:

$$
y=\mathbf{h x}+\epsilon_{o}+\epsilon_{m}+\epsilon_{b}
$$

53 Where $\mathbf{h} \in \mathbb{R}^{\mathbf{1} \times \boldsymbol{m}}$ is a STILT footprint, $\mathbf{x} \in \mathbb{R}^{\boldsymbol{m} \times \mathbf{1}}$ is the true gridded emission vector, $\epsilon_{o}$ is

54 instrument error and $\epsilon_{m}$ is model transport error, and $\epsilon_{b}$ is error in determining the background.

55 Since TROPOMI XCH4 represents a column averaged concentration, we must generate STILT

56 footprints at many altitudes, then take their pressure-weighted average, and finally smooth using

57 the TROPOMI averaging kernel, which is near uniform in the troposphere (Veefkind et al., 2012).

58 Here, we simulate STILT footprints at 50-m, 500-m, and 1000-m above surface, and assume that

59 sensitivity to surface emissions is negligible above these heights.

We collect all TROPOMI XCH4 over our observing domain and remove the background to

61 estimate $\mathrm{XCH} 4$ enhancements. For each $\mathrm{XCH} 4$ observation, we estimate the background as the $5^{\text {th }}$ 
62 percentile of all TROPOMI XCH4 within a $100 \mathrm{~km}$ radius of that observation. We simulate STILT

63 footprints for each TROPOMI XCH4 enhancement $\left(\mathbf{y} \in \mathbb{R}^{n \times 1}\right)$ such that we can expand Equation

64 S1:

$$
\mathbf{y}=\mathbf{H x}+\epsilon_{o}+\epsilon_{m}+\epsilon_{b}
$$

66 Where $\mathbf{H} \in \mathbb{R}^{n \times m}$ is the collection of STILT footprints, also called the Jacobian matrix. Each row 67 of $\mathbf{H}$ represents a unique STILT pressure-weighted column footprint.

68 Since we do not know the true emissions $\mathbf{x}$, we employ an atmospheric inversion to estimate 69 these values. Often inverse problems for $\mathrm{CH} 4$ have used a Bayesian framework (e.g., Rodgers, 70 2000), where prior emissions are used to constrain the optimal solution. However, the most recent 71 gridded prior for each basin that includes all sectors dates back to 2012 (Maasakkers et al., 2016), 72 which could mischaracterize the magnitude and spatial distribution of emissions given rapid 73 changes in many basins since 2012 (e.g., Permian; EIA, 2022). We apply an alternative approach, 74 called regularized regression that does not rely on a prior (Friedman et al., 2010). This approach, 75 sometimes called Tikhonov regularization, uses a regularization term (e.g., a flat prior) to stabilize 76 the solution. Here we seek a solution that balances model-data mismatch with the stability of the 77 solution:

$$
\hat{\mathbf{x}}=\min _{\mathbf{x}}\left\{\left\|\mathbf{R}^{-1 / 2}(\mathbf{y}-\mathbf{H} \mathbf{x})\right\|_{2}^{2}+\lambda^{2}\|\mathbf{x}\|_{2}^{2}\right\}
$$

79 Where $\mathbf{R}$ is the observational error covariance matrix, and the $\|\cdot\|_{2}$ term represents the $\mathrm{L}-2$ norm.

80 We find the solution by implementing coordinate-gradient descent (Friedman et al., 2010). The

81 parameter $\lambda$ is the regularization term, which can be estimated by analyzing an L-curve (Hansen et 82 al., 1993). In this process, many potential solutions are solved using a large array of fixed $\lambda$ values. 83 The solutions are then visualized on a 2-D plot, where the y-axis represents the first term of the 84 right hand side of Equation S3 (model-data mismatch) and the $\mathrm{x}$-axis represents the second term 
85 (L-2 norm of emission vector). The solution that occupies the lowermost left part of the plot (i.e., 86 the "elbow") is considered the optimal solution $\hat{\mathbf{x}}$. Figure S7 shows an example of an L-curve,

87 where one can select an appropriate $\lambda$ value. The error covariance matrix $\mathbf{R}$ accounts for instrument 88 error $\left(\sigma_{o}^{2}\right)$, transport model error $\left(\sigma_{m}^{2}\right)$, and error in background determination $\left(\sigma_{b}^{2}\right)$, which we 89 assume to be diagonal to speed computation, taking the following form:

$$
r_{i i}=\sigma_{o}^{2}+\sigma_{m}^{2}+\sigma_{b}^{2}
$$

91 TROPOMI column precision is reported to be approximately $0.7 \%$, which translates to roughly 11

$92 \mathrm{ppb}$. Studies have shown that STILT simulations with high $1 \mathrm{~km}$ resolution meteorological data

93 incurs approximately 4 ppb transport error (Cusworth et al., 2018). Given the coarser resolution of

94 HRRR winds, we assume $10 \mathrm{ppb}$ transport error here. We also estimate $17 \mathrm{ppb}$ variability in the 95 background. We populate the entries of $\mathbf{R}$ using these uncertainty parameters.

We estimate ensemble uncertainty on posterior fluxes by performing inversions following

97 Equation S3 on random samples of $\mathbf{y}$ for each inversion time period. Reported uncertainties

98 represent the $1 \sigma$ standard deviation of posterior flux estimates due to random sampling.

\section{Section S2.2: Validation of inversion algorithm}

The inversion algorithm described in Section S2.1 can be validated against multiple near-

102 simultaneous fluxes derived from independent observations. These include a tower network in the

103 Uinta Basin (Lin et al., 2021), a tower network in the Permian (PermianMap.org), and mass-

104 balance flights flown by Scientific Aviation in the Permian (PermianMap.org). For each of these

105 independent flux estimates, we clip our TROPOMI inverse flux grid spatially to match the grid of

106 the independent estimate. We compare our TROPOMI-derived inverse fluxes against these

107 observations in Table S1. Flux estimates from tower networks span time ranges akin to our

108 TROPOMI flux inversions, except for the Uinta, which represents a yearly average. Aircraft mass 
109 balance estimates represent a daytime average flux. However, relative differences between flux

110 estimates vary between $-36 \%$ to $42 \%$ across basins and time periods. These relative differences do

111 not exceed the $2 \sigma$ uncertainties of the TROPOMI flux inversions in any basin.

112 Table S1 also includes flux estimates for studies carried out asynchronously from our

113 campaigns and where spatial flux domains do not overlap (Marcellus, Denver-Julesberg). These

114 cannot be used for direct validation of our inversion approach, but are still useful for comparison.

115 Relative differences between these campaigns and our flux estimates vary between $-18 \%$ to $43 \%$, 116 again within $2 \sigma$ uncertainties of our flux estimates.

117

118 
120 Table S1: Validation of TROPOMI XCH4 flux inversion

\begin{tabular}{|c|c|c|c|c|c|c|}
\hline Basin & $\begin{array}{l}\text { TROPOMI } \\
\text { inversion } \\
\text { time period }\end{array}$ & $\begin{array}{l}\text { TROPOMI } \\
\text { derived } \\
\mathrm{CH} 4 \\
\text { fluxes }(\mathrm{t} \\
\left.\mathrm{CH}^{2} \mathrm{~h}^{-1}\right) \\
\end{array}$ & $\begin{array}{l}\text { Independent } \\
\text { measurement } \\
\text { system }^{\mathrm{a}}\end{array}$ & $\begin{array}{l}\text { Independent } \\
\text { measurement } \\
\text { system time } \\
\text { period }\end{array}$ & $\begin{array}{l}\text { Independent } \\
\text { flux rate }(\mathrm{t} \\
\left.\mathrm{CH} 4 \mathrm{~h}^{-1}\right)\end{array}$ & $\begin{array}{l}\text { Difference } \\
\text { relative to } \\
\text { independent } \\
\text { flux } \\
\text { estimate }\end{array}$ \\
\hline \multicolumn{7}{|c|}{ Spatial / Temporal Overlapping studies } \\
\hline Permian & $\begin{array}{c}\text { Sep-Nov } \\
2019 \\
\end{array}$ & $107 \pm 43$ & $\begin{array}{c}\text { Aircraft mass- } \\
\text { balance }\end{array}$ & Oct 17, 2019 & $167 \pm 31$ & $-36 \%$ \\
\hline Permian & $\begin{array}{c}\text { July-Aug } \\
2020\end{array}$ & $118 \pm 25$ & Tower network & $\begin{array}{c}\text { July-Aug } \\
2020\end{array}$ & 142 & $-17 \%$ \\
\hline Permian & $\begin{array}{c}\text { July-Aug } \\
2020\end{array}$ & $118 \pm 25$ & $\begin{array}{l}\text { Aircraft mass- } \\
\text { balance }\end{array}$ & Jul 13, 2020 & 123 & $-4 \%$ \\
\hline Permian & $\begin{array}{c}\text { July-Aug } \\
2021\end{array}$ & $112 \pm 27$ & Tower network & $\begin{array}{c}\text { July-Aug } \\
2021\end{array}$ & 134 & $-16 \%$ \\
\hline Uinta & $\begin{array}{c}\text { July-Aug } \\
2020 \\
\end{array}$ & $33.9 \pm 5.5$ & Tower network & 2020 & 24 & $42 \%$ \\
\hline \multicolumn{7}{|c|}{ Non-Spatial / Temporal Overlapping studies } \\
\hline $\begin{array}{c}\text { Denver- } \\
\text { Julesberg }\end{array}$ & $\begin{array}{c}\text { June-July } \\
2021\end{array}$ & $21.1 \pm 4.1$ & $\begin{array}{c}\text { Aircraft mass- } \\
\text { balance }\end{array}$ & $\begin{array}{c}2 \text { flights: } \\
\text { May } 2012\end{array}$ & $26.0 \pm 7.4$ & $-18 \%$ \\
\hline $\begin{array}{c}\text { Denver- } \\
\text { Julesberg }\end{array}$ & $\begin{array}{c}\text { Sep-Oct } \\
2021 \\
\end{array}$ & $25.2 \pm 6.8$ & $\begin{array}{c}\text { Aircraft mass- } \\
\text { balance }\end{array}$ & $\begin{array}{c}2 \text { flights: } \\
\text { May } 2012 \\
\end{array}$ & $26.0 \pm 7.4$ & $-3.1 \%$ \\
\hline Marcellus & $\begin{array}{c}\text { May-Jun } \\
2021\end{array}$ & $109 \pm 39$ & $\begin{array}{c}\text { Aircraft mass- } \\
\text { balance }^{\mathrm{c}}\end{array}$ & $\begin{array}{l}3 \text { flights; } \\
\text { Aug-Sep } \\
2015\end{array}$ & $76.3 \pm 7.2$ & $43 \%$ \\
\hline
\end{tabular}

121 andependent flux estimates from the Permian were retrieved from the Environmental Defense

122 Fund's PermianMAP (PermianMap.org). Flux estimates from the Uinta Basin can be found in Lin

123 et al. (2021), https://doi.org/10.1038/s41598-021-01721-5

124 bPetron et al., (2014), https://doi.org/10.1002/2013JD021272

125 'Ren et al., (2019), https://doi.org/10.1029/2018JD029690 


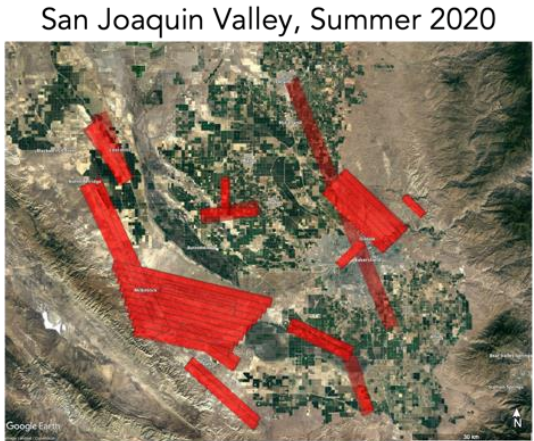

Denver-Julesberg, Summer 2021

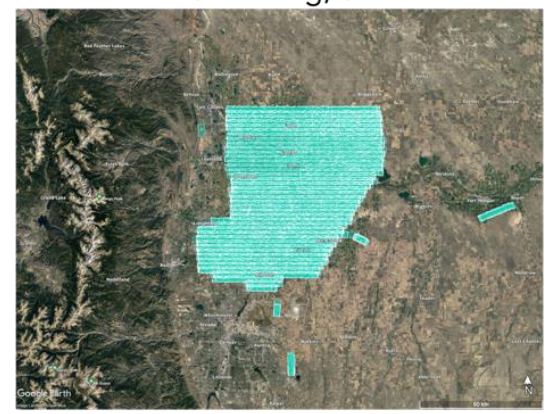

Marcellus, Spring 2021

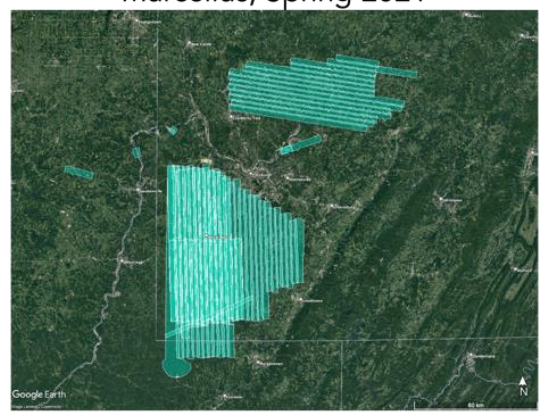

Permian, Summer 2021

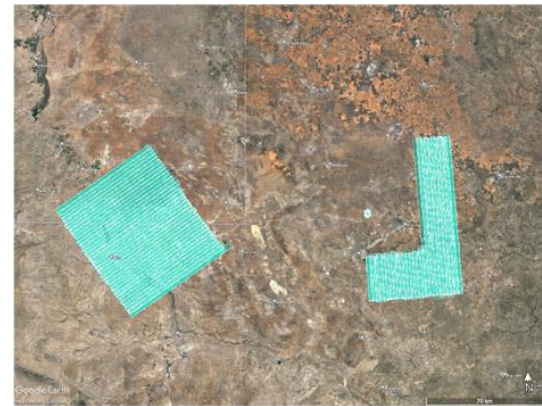

San Joaquin Valley, Fall 2020

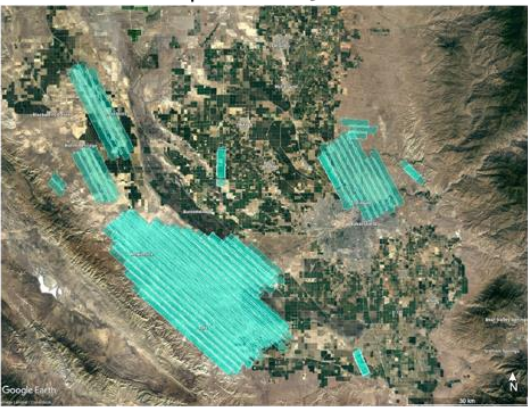

Denver-Julesberg, Fall 2021

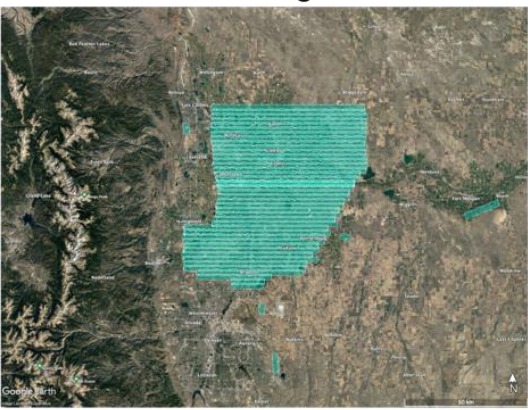

Permian, Fall 2019

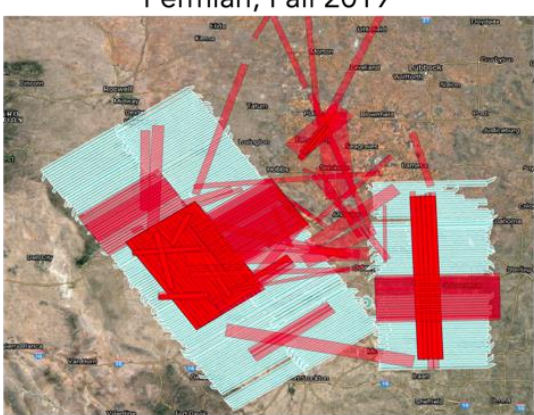

Permian, Fall 2021

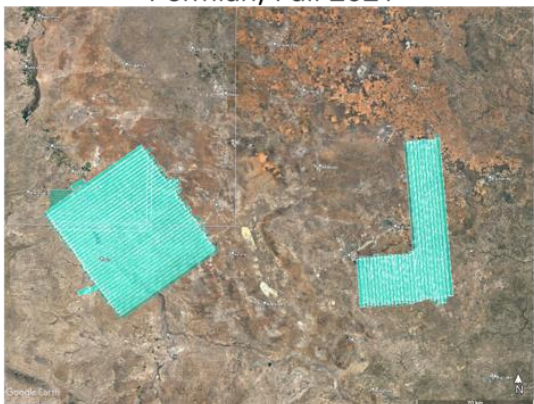

San Joaquin Valley, Fall 2021

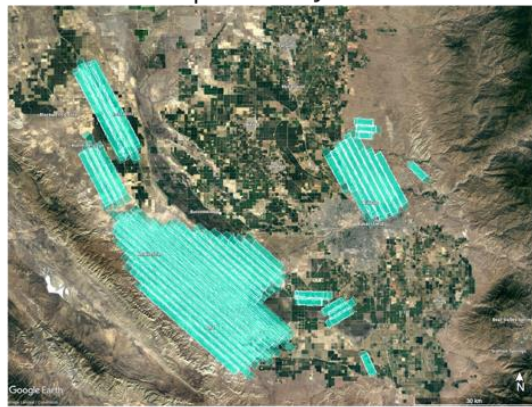

Uinta, Summer 2020

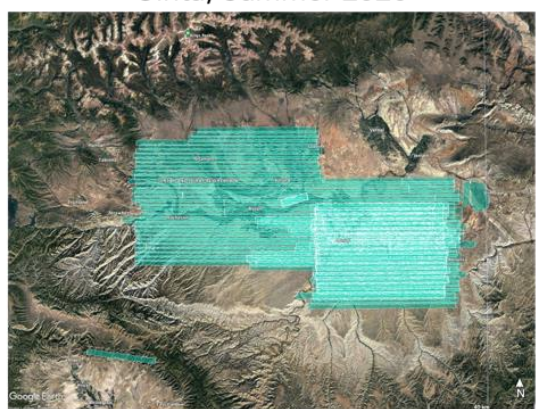

Permian, Summer 2020

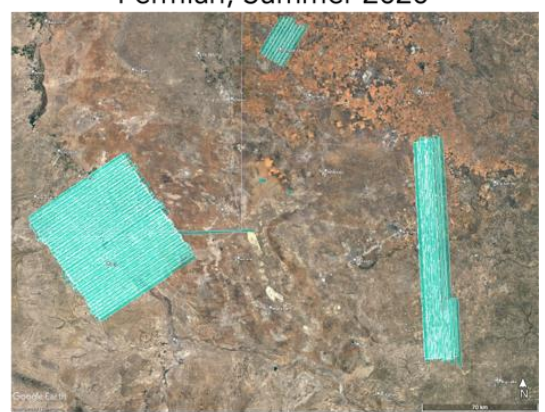

Figure S1. Flight lines overflown for each of the campaigns described in the survey. Red coloring 129 indicates lines that were flown with AVIRIS-NG. Teal coloring indicates lines that were flown with 130 GAO. 

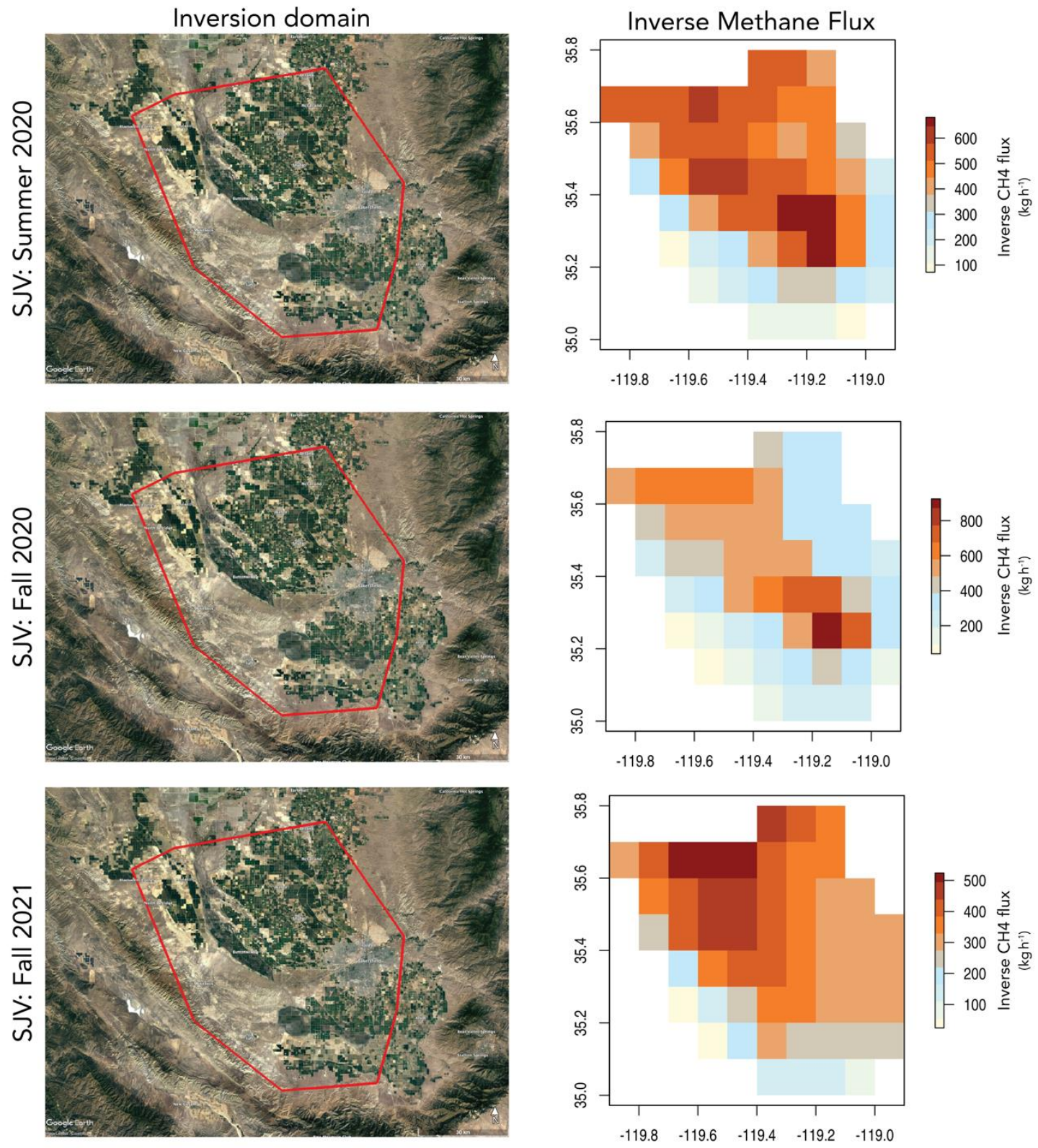

133

134 Figure S2. Regional TROPOMI-based flux inversions for the indicated basins and time periods. 135 Note that the colorbars are not consistent. 

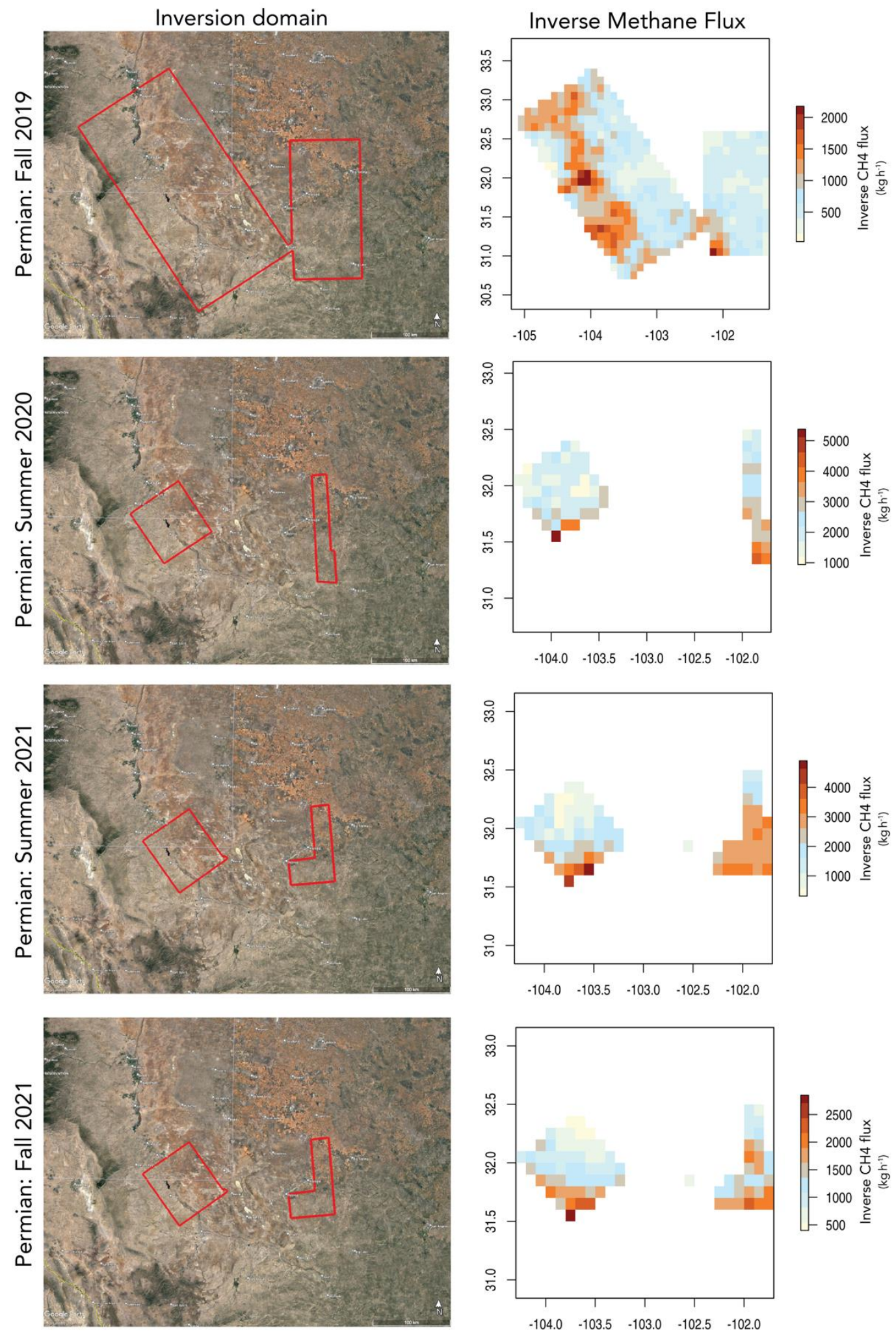
138 Figure S3. Regional TROPOMI-based flux inversions for the indicated basins and time periods. 139 Note that the colorbars are not consistent.
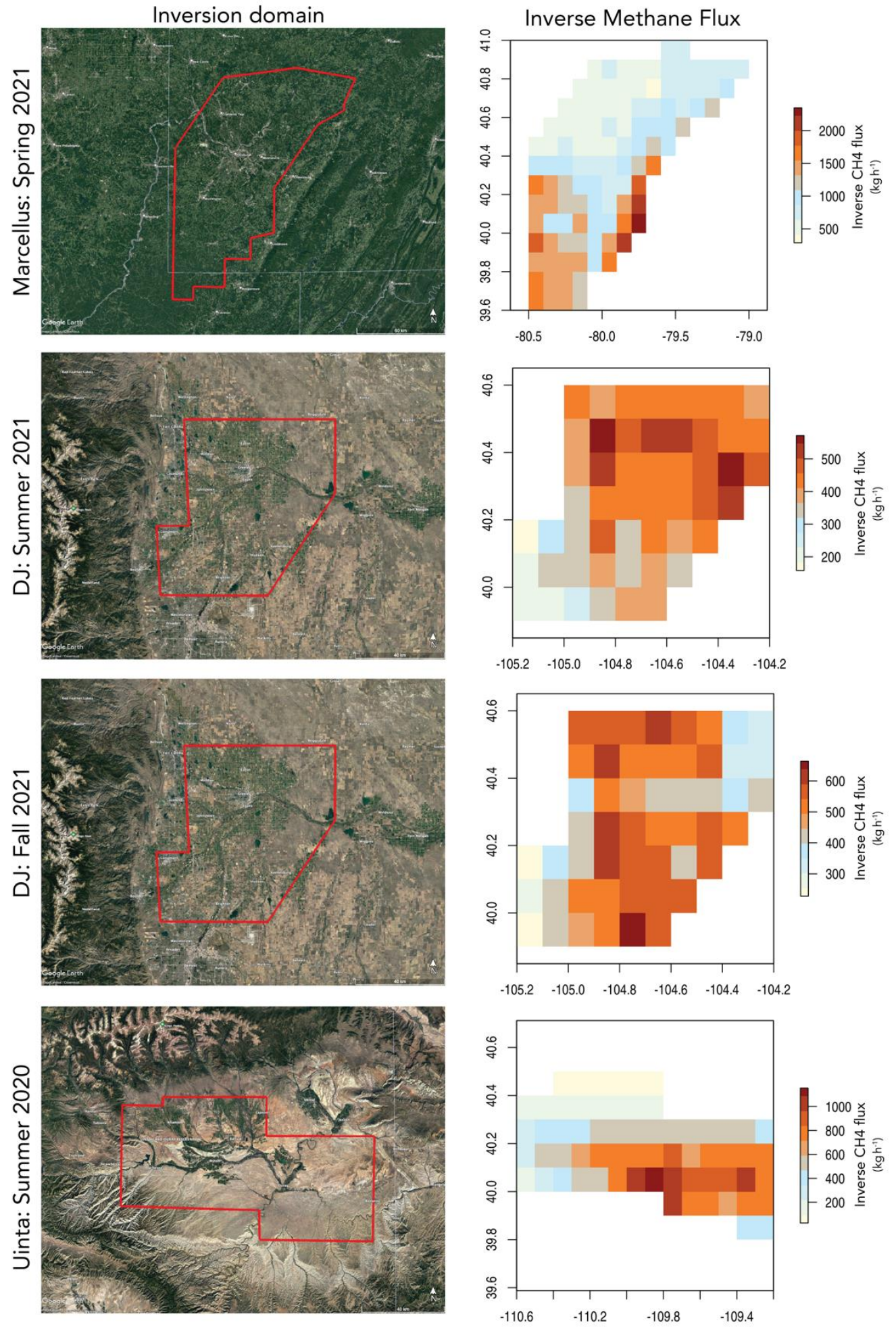
141 Figure S4. Regional TROPOMI-based flux inversions for the indicated basins and time periods. 142 Note that the colorbars are not consistent.

143 


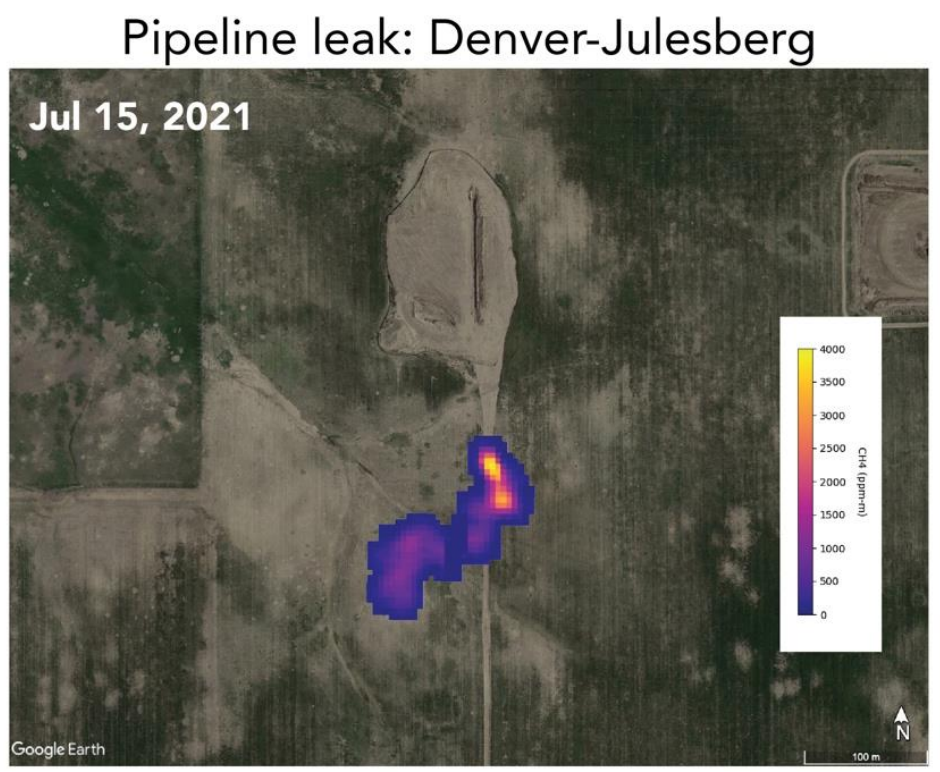

144

145 Figure S5. Pipeline leak that was detected just south of a shut-in well in the Denver-Julesberg basin 146 that was verified with ground-based monitors. 


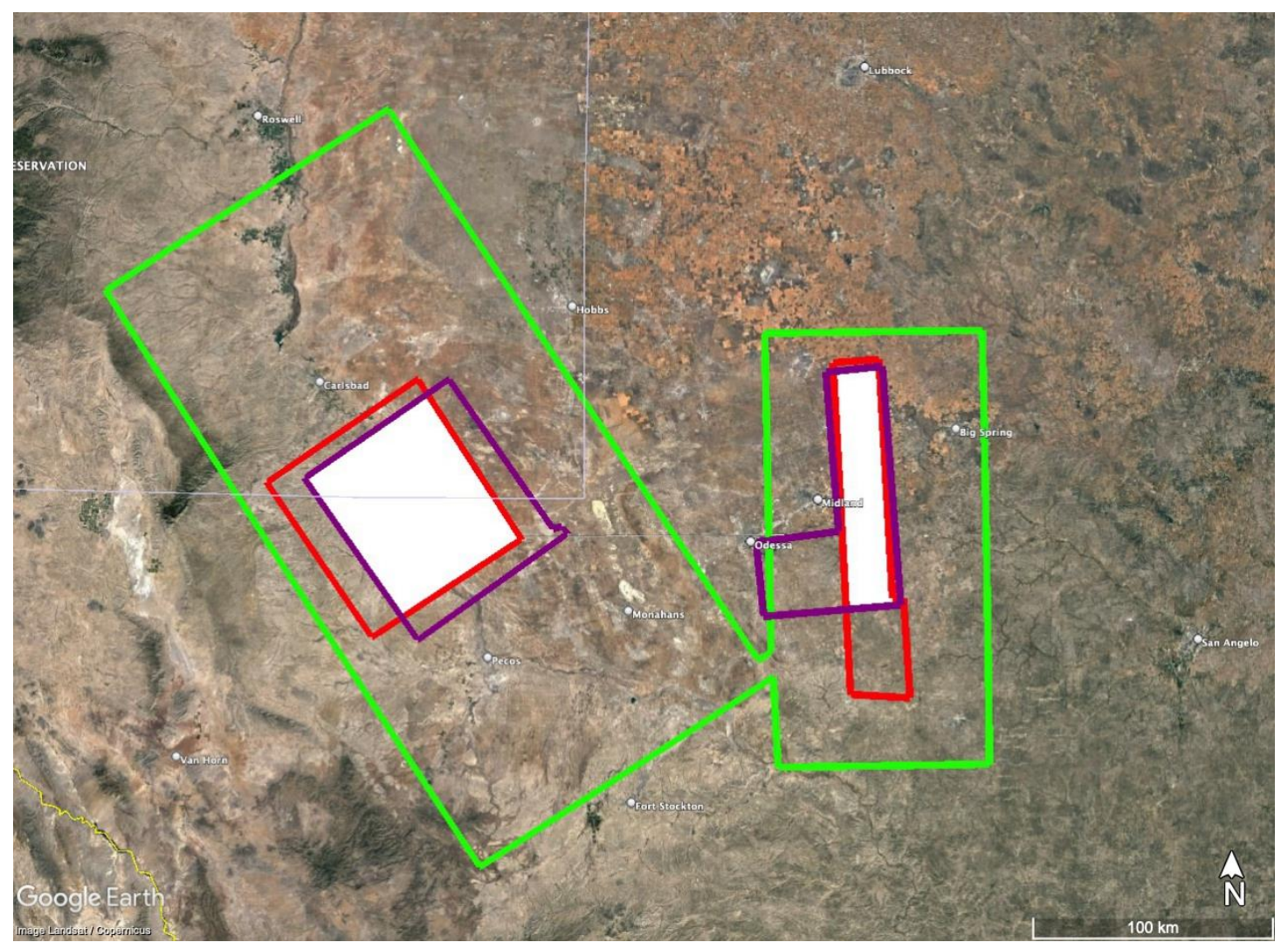

150 Figure S6. Domains for the Permian that correspond to the convex hull of airborne overflights 151 (Figure S1, S3). The inner white boxes represent the region of overlap across campaigns that were 152 used to assess trends in aggregated point source budgets. 


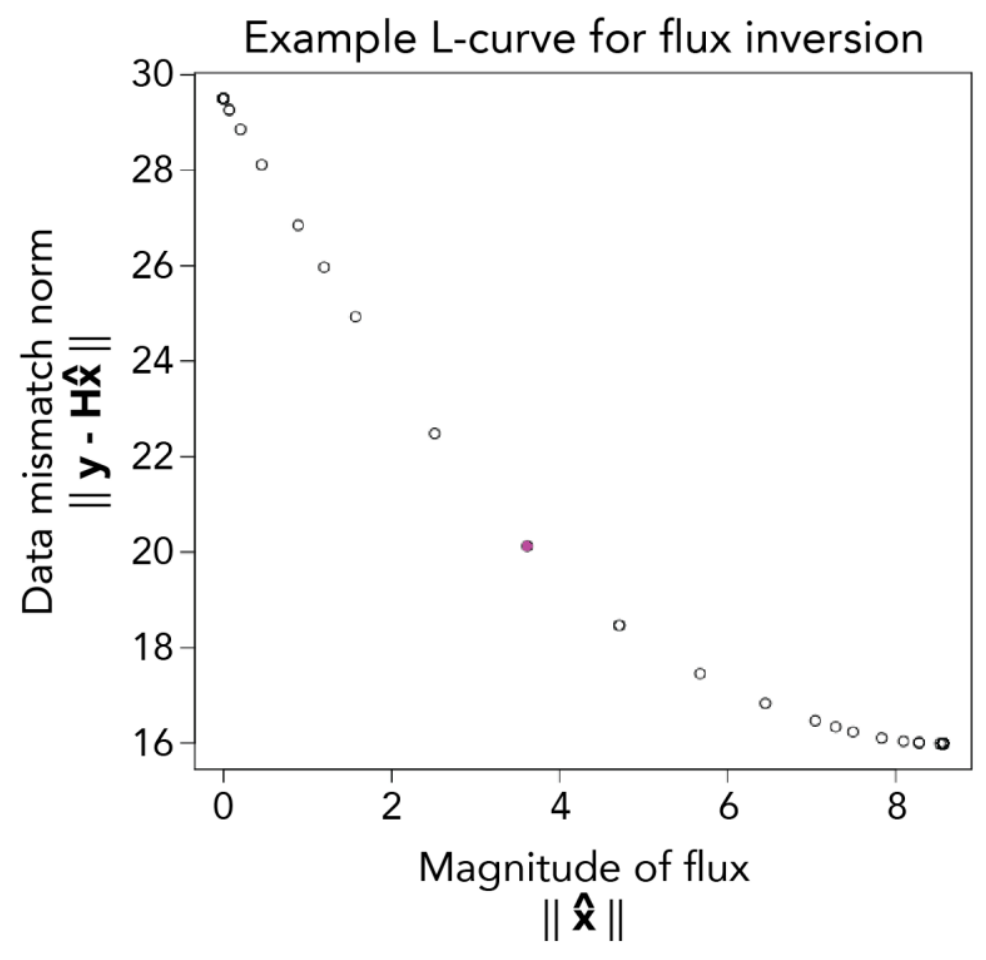

155

156

157

158

159

160

Figure S7. Example L-curve described in Section S2.1 that is used to identify an optimal regularization parameter (purple dot) for L-2 regularized regression. 

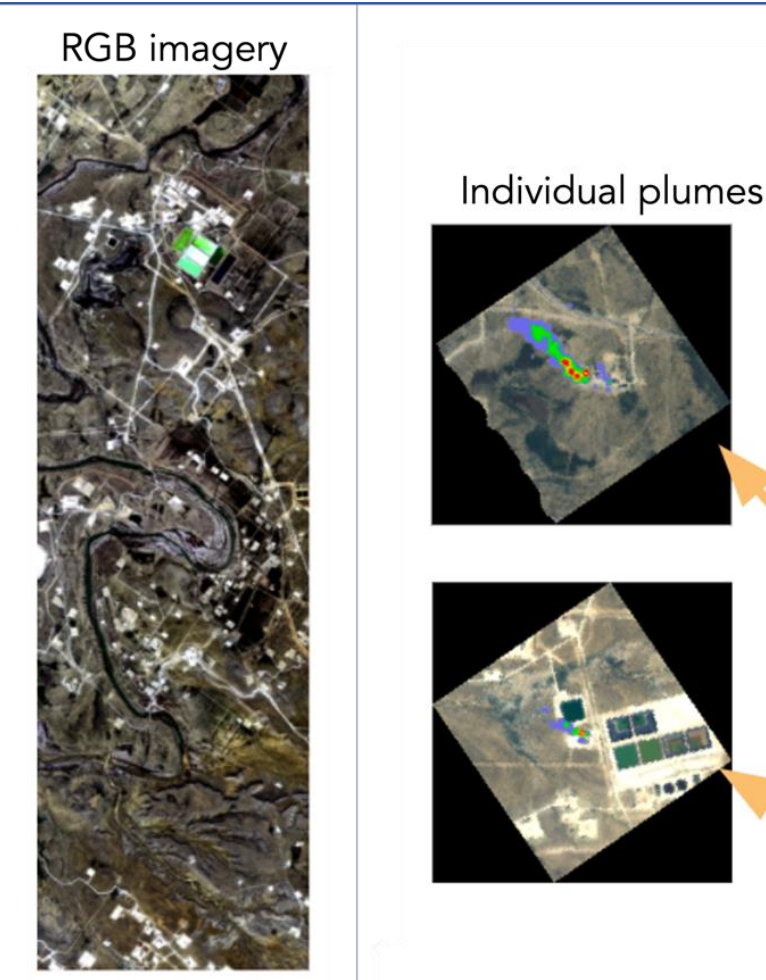

Fu

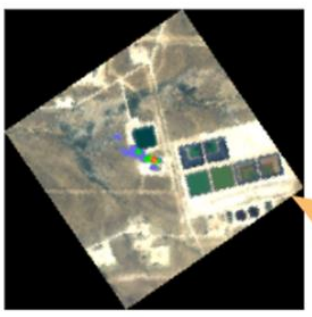

Full strip $\mathrm{CH} 4$ retrieval Individual plumes
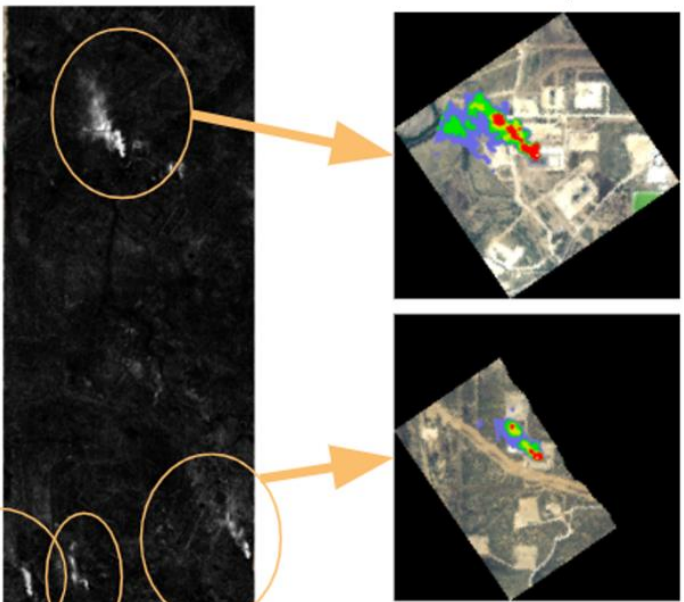

164

Figure S8. Example of full scene collect from AVIRIS-NG. The left panel shows RGB imagery from AVIRIS-NG. The right panel shows the full strip CH4 retrieval (black and white) that is used to identify plume geolocations, which are then used to generate unique plume imagery and quantify 165 emissions. 


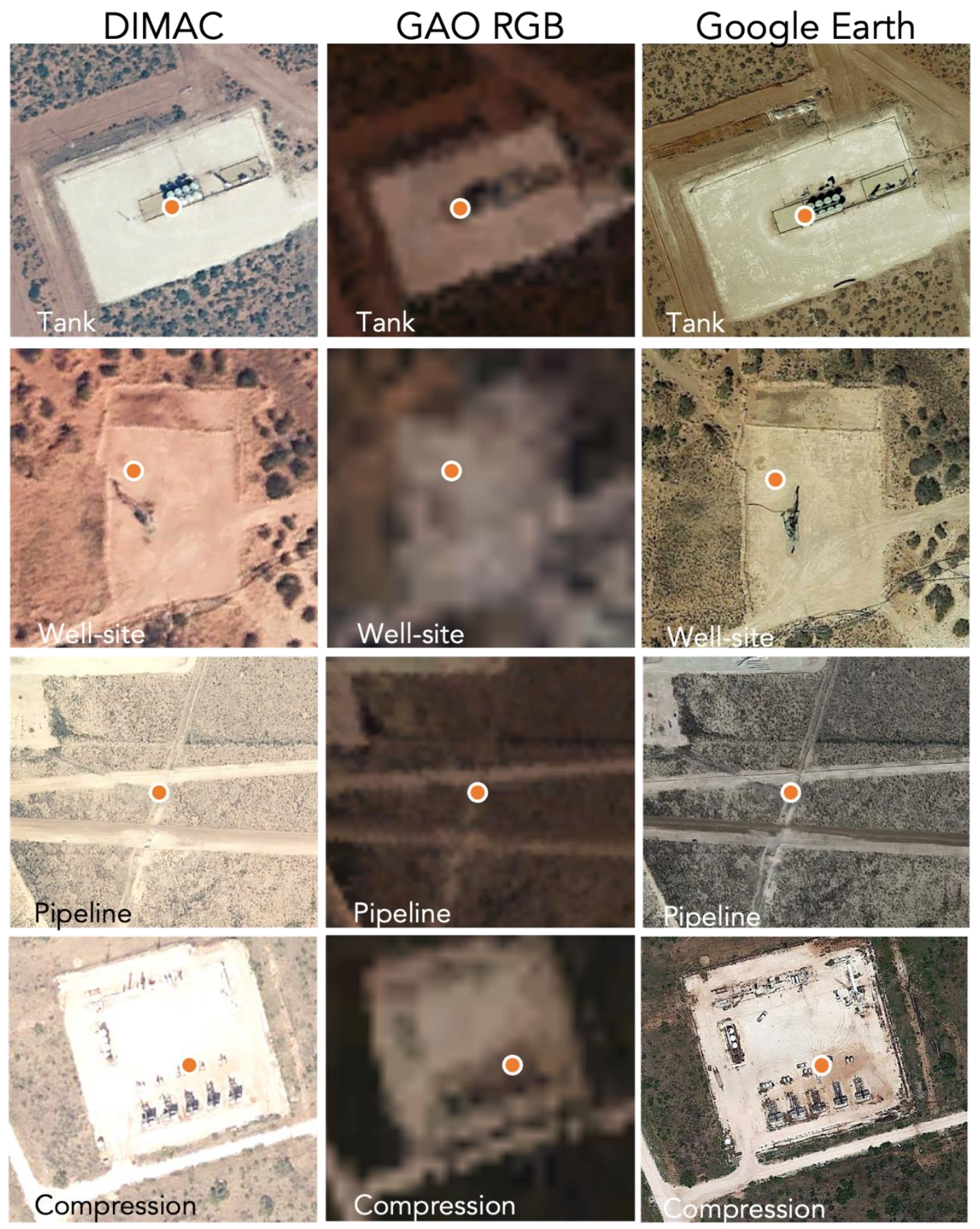

168

169

170

171
Figure S9. Examples of source attributions that were performed using GAO RGB, DIMAC, and Google Earth. 


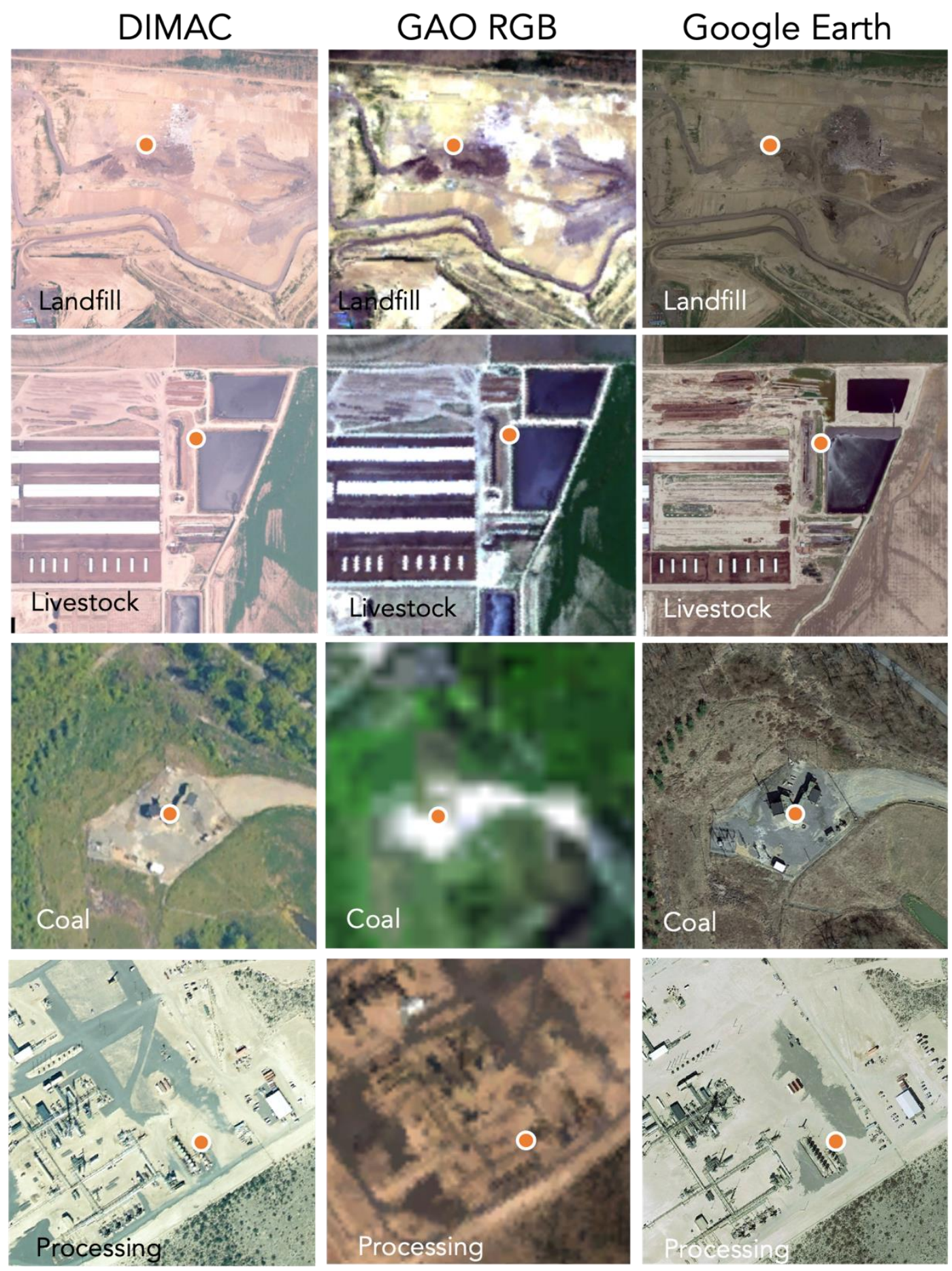

172

173 Figure S10. Examples of source attributions that were performed using GAO RGB, DIMAC, and 174 Google Earth.

175

176 


\section{SI References}

Cusworth, D.H., Jacob, D.J., Sheng, J.X., Benmergui, J., Turner, A.J., Brandman, J., White, L. and Randles, C.A., 2018. Detecting high-emitting methane sources in oil/gas fields using satellite observations. Atmospheric Chemistry and Physics, 18(23), pp.16885-16896.

Cusworth, D.H., Duren, R.M., Thorpe, A.K., Olson-Duvall, W., Heckler, J., Chapman, J.W., Eastwood, M.L., Helmlinger, M.C., Green, R.O., Asner, G.P. and Dennison, P.E., 2021. Intermittency of large methane emitters in the Permian Basin. Environmental Science \& Technology Letters, 8(7), pp.567-573.

Hansen, P.C. and O'Leary, D.P., 1993. The use of the L-curve in the regularization of discrete illposed problems. SIAM journal on scientific computing, 14(6), pp.1487-1503.

Fasoli, B., Lin, J.C., Bowling, D.R., Mitchell, L. and Mendoza, D., 2018. Simulating atmospheric tracer concentrations for spatially distributed receptors: updates to the Stochastic Time-Inverted Lagrangian Transport model's R interface (STILT-R version 2). Geoscientific Model Development, 11(7), pp.2813-2824.

Friedman, J., Hastie, T. and Tibshirani, R., 2010. Regularization paths for generalized linear models via coordinate descent. Journal of statistical software, 33(1), p.1.

Lin, J.C., Bares, R., Fasoli, B., Garcia, M., Crosman, E. and Lyman, S., 2021. Declining methane emissions and steady, high leakage rates observed over multiple years in a western US oil/gas production basin. Scientific reports, 11(1), pp.1-12.

Maasakkers, J.D. et al. Gridded national inventory of US methane emissions. Environmental science \& technology, 50(23), pp.13123-13133. (2016)

Pétron, G., Karion, A., Sweeney, C., Miller, B.R., Montzka, S.A., Frost, G.J., Trainer, M., Tans, P., Andrews, A., Kofler, J. and Helmig, D., 2014. A new look at methane and nonmethane hydrocarbon emissions from oil and natural gas operations in the Colorado Denver-Julesburg Basin. Journal of Geophysical Research: Atmospheres, 119(11), pp.6836-6852.

Ren, X., Hall, D.L., Vinciguerra, T., Benish, S.E., Stratton, P.R., Ahn, D., Hansford, J.R., Cohen, M.D., Sahu, S., He, H. and Grimes, C., 2019. Methane emissions from the Marcellus Shale in Southwestern Pennsylvania and Northern West Virginia based on airborne measurements. Journal of Geophysical Research: Atmospheres, 124(3), pp.1862-1878.

Rodgers, C.D., 2000. Inverse methods for atmospheric sounding: theory and practice (Vol. 2). World scientific.

Veefkind, J.P. et al. TROPOMI on the ESA Sentinel-5 Precursor: A GMES mission for global observations of the atmospheric composition for climate, air quality and ozone layer applications. Remote sensing of environment, 120, 70-83. (2012) 